\title{
اشتغالات فلسفة التاريخ من الاصول حتى الاصطلاح
}

م ـ ـد ـ ـ حامد عبد الحمزة محمد علي

جامعة بابل كلية التربية للعلوم الانسانية مدية

\section{المقدمة}

تذهب دراستنا موضوع البحث ، الى الوقوف على بو اكير التفكير الفلسفي للتاريخ ، و على الرغم من اننا لم نجد فلسفة التاريخ كاصطلاح في الفلسفة ودر اسات التاريخ ، حتى جاء به الاديب و الفيلسوف الفرنسي فولتير ـ. لكن هذا لا يصر ح لنا القول بعدم وجود تفكير تأملي وتحليلي وباطني وتفحصي للتاريخ قبل الاصطلاح ، من هذا جاءت در استنا كمحاولة لإيجاد ما ذهب اليه أصحاب العلاقة في تفكير هم الفلسفي للتاريخ ، فقمنا بتتبع ابرز الإشار ات و التتبيهات ، و التي تطورت الى نظريات عند الفلاسفة منذ تلك اللحظات التاملية التي شكلت الفلسفة اليونانية وحتى ظهور المصطلح ـ وفلسفة التاريخ تذهب الى عدم عد التاريخ دراسة لأحوال الماضي فحسب ، بل ما يعطي التاريخ خصوصيته كونه يبحث في تعاقب الحوادث وتطور فعل الانسان على مر الأزمان ، و الزمان هو احد اهم ركائز التاريخ والذي لا تاريخ من دونه ، و هو يحمل في مسيرته تللك النقاط التحولية لمر احل الامم المختلفة ، كذلك الحال بالنسبة الى المكان الذي اتفق الفلاسفة والمؤرخون على انه من اهم اركان المسرح التاريخي فلا تاريخ بدون مكان ، اما الانسان فقد كان المكمل الرئيسي للدائرة التاريخية ، ولان الانسان من ضمن دائرة التاريخ ، كان لا بد من ان يحمله الى بـ محمل العقل والادر الك ، والانسان صاحب التفلسف صور لنا تلك المر احل التي مر بها الانسان و هو يتأمل تاريخه ، فقدم لنا تاريخ عقل متفلسف في التاريخ ، ونحن هنا سلطنا الضوء على تلك اللحظات التي تأمل بها الانسان التاريخ بلغة الفلسفة حتى فولتير، من هذا جاءت در استنا بمبحثين . الاول حمل عنوان (نشأة فلسفة التاريخ - الاصول) ، وجاء بمطلبين : الاول، بحثنا فيه التاريخ عند ابرز حضار ات الثرق القديم ، حضارة و ادي الر افدين ، وحضارة و ادي النيل ، وحضسارة الصين ، اذ حاولنا تسليط الاضواء على تلك الأفكار القديمة في تلك الحضار ات التي كانت تحمل دلالات التفكير الفلسفي في التاريخ ، وما تحمله هذه الحضار ات من مضمون فكري بعمق تاملي لدراسة 
التاريخ ، اما المطلب الثاني ، فقد خصص للبحث عن جذور فلسفة التاريخ عند اليونان والرومان ، ولهذا المطلب اهمية بالغة ، اذ ان اليونان على وجه الخصوص قد مثلو ا مرحلة الانتقال من الله الى الانسان وهم اول من شرع يفكر فلسفيا بالمعنى التنظيمي للتفكير ، فكانت طريقة التفكير بالتاريخ لديهم هي السؤال عن كل ماهو استفهام ؟ وذذا التفكير الذي اخذ يحمل طابعا علميا قد اختلف في مضمونه عن التفكير القديم ، وبهذا فان طريقة التفكير بالتاريخ اخذت صفة العلم ـ اما المبحث الثاني ، فقد حمل عنوان ( الظهور وتطور المصطلح ) ، وتكون من مطلبين : الاول ، تحت تسمية ظهور فلسفة التاريخ ، وفيه تم دراسة اهم النظريات في التاريخ وابرز فلاسفتها ، وكان ابرزهم القديس (او غسطين) و العلامة (ابن خلدون) ، و لأهميتهما في در اسة المؤر خ و الفيلسوف فاستوجب الامر التوقف عندهما لاغناء البحث بافكار هما التي ماز الت حية وقائمة برغم تطور الاصطلاح و المفهوم ، اما المطلب الثاني ، فقد تعلق بنطور المصطلح في عصر النهضة عند الفلاسفة الذين سبقو ا فولتير ، و عند فولتير، ايضا الذي اشتهر بانه صاحب اصطلاح فلسفة التاريخ المبحث الأول ـ نشأة فلسفة التاريخ (الأصول ) . المطلب الاول : التاريخ عند ابرز حضارات الشرق القديم . لا مناص من القول ، ان الحديث عن تسمية فلسفة التاريخ قبل ظهور المصطلح ، على لسان فولتير ـ 1694- 1778 (1) وقبل ان ينقسم ، الى فلسفة تاريخ مثالية ، و أخرى نقدية . كان حديث في الفكر التاريخي ، من خلال محاولة تسليط الأضواء على الوقائع التاريخية ، بغية تحليلها ومحاولة الاستفادة من تجاربها ، لغرض التنبؤ بحوادث المستقبل ـ فكانت محاو لات للتفكير في سبر أغوار الوعي التاريخي ـ ويبدو ان الوعي التاريخي هو أساس فلسفة التاريخ باصطلاحها الحديث. .

1 ـ فر انسو اماري ارويه دي فولتير ، فرنسي ، ولد في باريس لأسرة برجوازية ، وتعلم في الكلية اليسوعية ، وترك دراسة

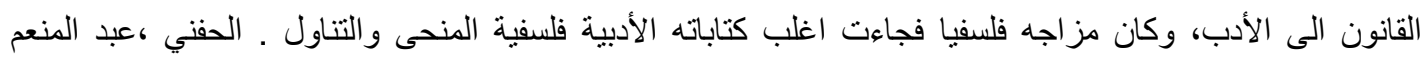

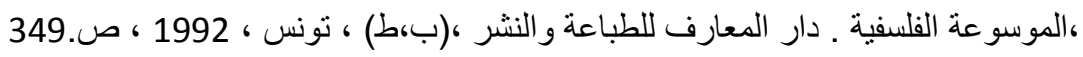


بل هو البديل الفعلي له قبل التسمية ـ وقد لحظنا ان هيجل .1831-1770(2) قد أكد بعد عصور طويلة دن تشخيص الوعي كأساس لدر اسة التاريخ ـ وتحديدا في القرن التاسع عشر ، ان التاريخ هو الوعي بالحرية ـ بيد ان الوعي بالتاريخ ليس مقصور ا على من بدأوا استخدام لفظ التاريخ ، أو على من كتبو ا المؤلفات التاريخية الكاملة مستخدمين فيها مناهج بعينها ـ فالوعي بمعنى التاريخ وأهميته قد نشكل مع أول من سجل وثثقة يصف فيها انجاز ات البشر في اي مجال من المجالات . و عليه فأن الوعي التاريخي وأهمية التاريخ قد بدأ منذ فجر الحضارة البابلية ، وكذلك المصرية ، وحضارات الثرق الأخرى . حيث بدأ الانسان يعي أهمية تسجيل الأحداث التاريخية الكبرى ونسبتها الى صانعيها من الملوك والحكام ، فالنقوش الأثرية على جدران المعابد لا تزال شاهدة على العناية الكبرى التي أولاها هؤلاء الملوك لتسجيل منجز اتهم ومعاركهم الحربية التي ساهمت في تطوير ممالكهم وفي توسيع رقعتها ، كما ان أدبيات الحضار ات الثرقية المختلفة تكثف عن عمق الايمان بأهمية تسجيل ما حدث في العصور السحيقة والاستناد على امجاد الشعوب السابقة في امكانية النهوض من جديد وصنع الحاضر الزاهي الذي يحلم به الجميع وعلى رأسهم كتاب البرديات و الملاحم والأدبيات المختلفة ـ ومن أمثالها ، ما كتبه ايبوور ونفرر و هو في مصر القديمة ، وما تذكره ملحمة جلجامش في العر اق القديم ، وكتاب التغيرات yking في التراث الصيني القديم فضلا عما جاء في كتاب التاريخ لكونفشيوس ـ ومن خلال الدراسة المتعمقة لهذه الوثائق و الكتابات التاريخية في حضار ات الثرق القديم ، يمكن ان تكثف أمامنا بما لا بدع مجالا للثك ان لدى هذه الحضار ات من عني بتسجيل المنجزات الحضارية سواء أكانت احداثا سياسية او مواقع

2 - فيلسوف ألماني ـ ولد في شنوتغارت ، ومات بالكوليرا في عام 1831 في برلين .وقد كان ابنا لمستخدم في الإدارة

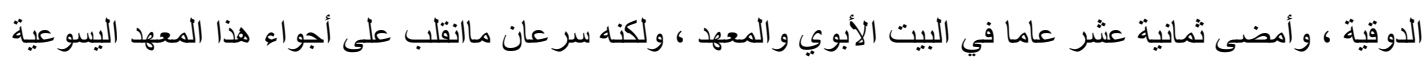

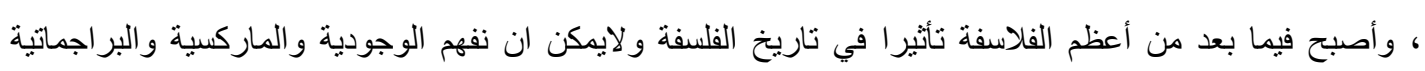

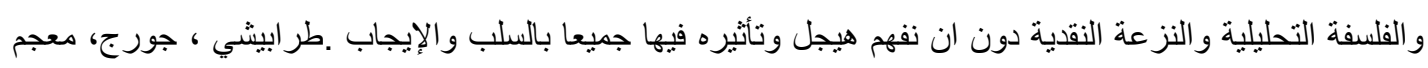
الفلاسفة . دار الطليعة ، ط3 ، بيروت ، 2006 ، 721. 
حربية ـ أو مكتشفات علمية في مختلف العلوم أو كانت نظريات فلسفية بلورها مفكرو هذه (3) الحضار ات.

و إحساس الإنسان في الحضار ات القديمة ، بالزمن و الخوف من الموت قد جعل من الكتابة أعظم وسيلة لحفظ الآثار الخالدة ،. ولن يجد الإنسان في تاريخ الشرائع كلها الفاظا ارق و أجمل من ألفاظ ملك بابل الثهير حمورابي .." فليأت اي إنسان مظلوم له قضية امام صورتي انا ملك العدالة ، وليقرأ النقش الذي على اثري ، ليلق باله الى كلماتي الخطيرة ، ولعل اثري هذا يكون هاديا له في قضيته " ، ويختم شاعر مملكة مصر الوسطى (بتاح حتوب ) حوالي 2800 ق.م. تعاليمه بهذه العبارة الدالة على إحساس عميق بالمستقبل " لن يمحى من هذه البلاد الى ابد الدهر لفظ من ألفاظ

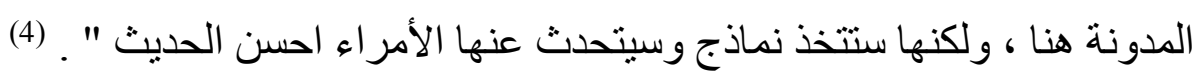
ويبدو لنا ، ان الإنسان لما كان كائناز منيا ، فأن التفكير بالتاريخ جزء من اشتغالاته ، وكل نظرة في التاريخ تظهر موقف الإنسان من الزمان فالإنسان هو الكائن الزماني الوحيد ، لأنه مفطور على حاستي الذاكرة و التوقع ، إذ انه ينظم حياته داخل شبكة نسيجها الماضي و الحاضر و المستقبل ، هذا

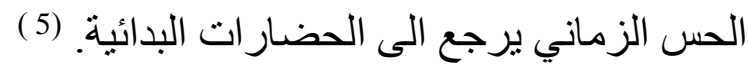
فنجد ان الخوف من الموت ورغبة الإنسان في الخلود تعد من اقوى الدوافع التي حفزت الإنسان منذ اقدم العصور الى التفكير في الزمان على انه تغير مستمر ، ومن ثم جعله يبحث عن معنى

3 - ينظر: النشار ، مصطفى حسن . فلسفة التاريخ معناها ونشأتها واهم مذاهبها .دار المسيرة للنشر والتوزيع والطباعة

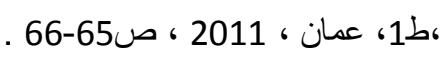
4 - ديوارنت ، ول ، قصة الحضارة ، نشأة الحضارة ، الثرق الأنىى .نر، زكي نجيب محمود ، جامعة الدول العربية ، الإدارة الثقافية ، ظ3 ، القاهرة ، 1965 ، 151 ، 151 . 5 ـ ينظر : ويلسون ، كولن . جرانت ،جون ـ فكرة الزمان عبر التاريخ ، ترجمة فؤاد كامل ، مراجعة شوقي جلال ، مجلة

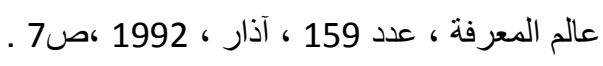


المصير الذي ينتظر الإنسان بعد الحياة ـ (6) فلم تكن ملحمة جلجامش إلا تمثيلا لذلك الصر اع ، محاولته اليائسة التشبث بالوجود ، مدفو عا بغريزة حب الحياة و الحفاظ على البقاء ." ما الذي حملك على هذا السفر البعيد ؟ أجاب جلجامش : جئت لاسأل عن (لغز الحياة والموت ) ، و علام تهيم على وجهك في الصحارى ؟ انه "انكيدو " صاحبي وخلي الذي احبيته حبا جما لقد انتهى الى ما يصير إلبه البشر جميعا ؟ فأجابت صاحبة الحانة : الى اين تسعى يا جلجامش ان الحياة "يقصد الأبدية " التي تبغى لن تجد حينما خلقت الالهة العظام البشر قدرت الموت على البشرية وأستأثرت هي (7). بالحياة

إذن الفكر التاريخي يتمثل في الموقف العقلي الذي يتخذه الإنسان إزاء الحوادث التاريخية ، وقد وجدنا هذا الموقف يتبلور منذ أقدم العصور في الثرق القديم ، لكنه لم يتحول الى نظرة فلسفية كلية متسقة الى التاريخ ـ لكن هذا لا يعني بأي حال من الأحو ال انه ظل موضو عا للتأمل الميتافيزيقي . بل يمكن القول ان الكثير من المحاولات قد بذلت من مفكري العصور القديمة ، للنفاذ الى جوهر العملية التاريخية ومحاولة معرفة اتجاهاتها ، فلقد كان التفسير الأسطوري للتاريخ هو السائد . ولقد زخرت الذاكرة البشرية بزخم واسع من الأساطير ، كأسطورة جلجامش ، وأسطورة الخلق و التكوين و الطوفان ـ. ويعد هذا الضرب من التدوين التاريخي شبيه التاريخ الذي لا يسجل ما حدث فعلا بل ما حسه الناس وأحبه أو اعتقدوا في أوقات مختلفة بأنه قد حدث . . ويرى علي حسين الجابري " ان الأسلاف قبل خمسة ألاف سنة قد تمكنوا من دخول مرحلة العصور التاريخية حينما 6 ـ السو اح ، فراس ـ مغامرة العقل الأول ، الدراسة في الأسطورة ، دار الكلمة ، ط2 ، بيروت ، 1981 ، ص2 . 7 ـ ينظر : باقر، طه ـ ملحمة جلجامش ـ منشورات وزارة الاعلام ، الجمهورية العر اقية ، سلسلة الكتب الحديثة ، (ب،ط) ، بغداد ، 1975 ، ص112-116-116- 120 ـ و. برستد ، انتصار الحضارة ، نرجمة احمد فخري ، مكتبة الانجلو

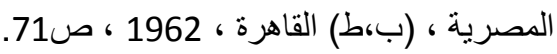


اكتشفو الكتابة والتدوين التاريخي ، متجاوزين آثار الكوارث و المصاعب الطبيعية ، وفي مقدمتها الطوفان حتى بدا لنا كأن المعنى الباكر للتاريخ هو الثاهد المدون" .(8) و الاثار تمثل ذلك الحاضر المتجدد في نقل تجارب الانسان ، ولقد أوضحث المكتشفات الآثارية ان بلاد وادي الر افدين ، قد عبرت عن إحساسها بالتاريخ من خلال اهتمامها بتسجيل تجارب الأجيال الماضية ، وخبر اتها ومنها أعمال الملوك و الحكام ، ومحاولة تفسير التاريخ البشري العام بالرموز الأسطورية مثل خلق الانسان ومكانته في نظام الكون والحياة وظهور المجتمع وأنظمة الحكم ـ وقد استخدم العراقيون القدماء حادثة الطوفان كحد فاصل بين التاريخ القديم والتاريخ الحديث ، وكان من اهم المدونات التاريخية التي وصلت الى ايدينا عن العراق القديم جداول الملوك و هي : ثبت بأسماء الملوك و السلالات وسني حكمه ، نظمها الكتبة عند مطلع الالف الثاني قبل الميلاد ، واثهر هذه الجداول ، هي جداول الملوك السومريين التي ذكرت اسماء وسني حكم

(9). الملوك الذين تعاقبو ا على حكم البلاد منذ أقدم العصور السابقة للطوفان وحتى تاريخ تدوينها إذن لا شك في القول ، ان الوثائق والآتّأر مصدر ا اوليا للتاريخ ، من خلالها كان البحث جاريا لمعرفة الوعي المبكر والاحساس بالتاريخ ، فقد شهدت أقدم العصور التاريخية تسجيل احداث بالرسم او النقش على الحجر ، ومع تطور الحضارة وازدهار ها اخذ التاريخ يشكل أساسا جوهريا في تسجيل الاحداث و اصبح بمثابة السجل الذي يحفظ الاحداث و الأفكار والأعمال ، ومن خلال تتبع مسيرة الحضارة الإنسانية ، يمكن القول ان بداية التاريخ ، الذي شكل الحضارة ، كان عبارة عن صراع بين الانسان ومحيطه لغرض ادامة الحياة . وان واقع الحياة الانسانية يمثل أساس التاريخ و مادته على الرغم من ان التاريخ لم يأتي وصفا معبر ا للحادثة ، إنما جاء تعبير ا عن علاقة تبادلية بين الواقع كتاريخ وبين الفكر كتصور شمولي ، ويمكن تحديد ذلك من خلال تحليل

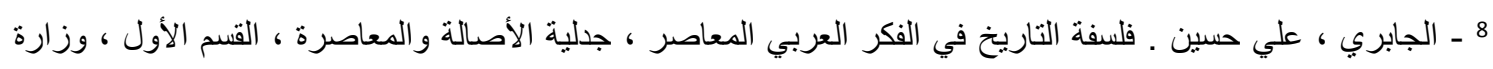

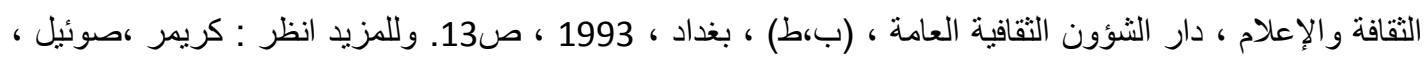

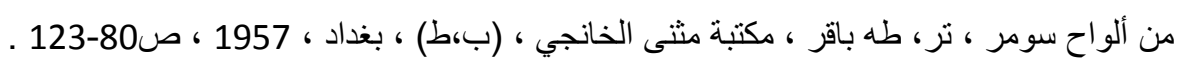
9 - ينظر : الملاح ، هاثشم يحبى ـ المفصل في فلسفة التاريخ ـ دار الكتب العلمية ، ط1، بيروت ، 2007 ،ص47. 
النصوص القديمة .(10) و على الرغم من ان المدونات كانت مدونات عامة لم تنسب كتابتها الى كاتب معين او مؤرخ متخصص ، فأن تاريخ العراق القديم لم يخل على ما يبدو من وجود مثل هؤلاء الكتاب ـ فقد أثير الى وجود مؤرخ عراقي اسمه (بروعشا ) عاش في القرن الثالث قبل الميلاد ـ وقد اسماه اليونان (بيرسوس) ـ وقد الف كتابه في تاريخ بابل باللغة اليونانية ، وكان هذا الكتاب مصدر ا مهما للمؤرخين في العالم الإغريقي - الروماني وذللك لندرة المصادر الاخرى . وفي بلاد وادي النيل فأننا نلاحظ ان الوعي التاريخي لاى المصريين القدماء تمثل بوضع التقويم الثمسي في نحو سنة 4236 ق.م. وكان هذا التقويم يقوم على أساس تقسيم السنة الشمسية الى ثلاثمائة وخمسة وستين يوما ـ وفي دلالة الوعي التاريخي أيضا لدى أهل وادي النيل ، انهم للفترة ما بين 3400 ق.م. - 2700 ـ وفي احدى الحوليات التي اشتهرت بأسم (بالرمو) حيث طر أ بعض التغير في عملية تمييز السنين والتعرف عليها ، عندما اعتبر عهد كل ملك من الملوك فترة مستقلة بذاتها ـ وكذلك تشير المصادر الى وجود مؤرخ مصري عاش في القرن الثالث قبل المبلاد ، وكان معاصر ا للمؤرخ العر اقي برو عثـا ، وقد عرف بأسم مانيتو. (11) وفي نفس السياق ، فأن من المحاو لات القديمة لتدوين التاريخ ، تلك التي قام بها الكاهن المصري القديم مانيثون Manetho الذي عاصر بطليموس الأول ، وبطليموس الثاني ـ ووضع تاريخا لقدماء المصريين ، استمدت مادته من مصادر مصرية قديمة ـ وكان ذلك نظام الحوليات اي تدوين الحو ادث وترتيبها تاريخيا عام بعد عام ـ وللاسف فقد مؤلف مانيثون هذا ، فلم تبقى منه الا نبذ قليلة ـ وأيضا فقد كتاب آخر لمؤلف بابلي أسلفنا اسمه هو بيروسوس Berossus ، عاش حوالي 250 . ق.م ، كتابه تاريخ بابل باليونانية مستندا على مصادر بابلية قديمة . وقد ضاع مؤلفه ايضا ولم تصلنا منه الا نبذ بسيطة متضمنة في بعض الكتب الأخرى ـ وحذا بعض الأشوريين ، و العبر انيين حذو المصريين و البابليين في هذا المجال فكتبو ا عن تاريخ أثور وبابل ، و هذه الكتابات انما تعبر عن محاو لات في در اسة التاريخ ، من خلال جمعه و النظر البه بنظرة كلية ، و البحث في الأسباب 10 - ينظر : الدليمي ، حامد حمزه حمد .فلسفة التاريخ والحضارة .دار الطيف للطباعة ، (ب،ط) ،واسط ، 2004 ،40-39. 11 ـ ينظر : الملاح ، هاثثم يحيى ، المفصل في فلسفة التاريخ . المصدر نفسه ، ص48-49. 
التي أدت الى نتائج بعيشونها ، وسلطوا الضوء على الاهنمام بمصادر تاريخهم والتي تمثل ماضييهج وحاضر هم في الوقت ذاته . ولعل الأسطورة ، هي ابرز مصادر كتابة التاريخ ، ولعلها ايضا من ابرز مصادر تفسير التاريخ لديهم، فقد شغلت موقعا بارز افي الحياة الفكرية والروحية لأمم العالم القديم ـ وكان للأساطير علاقة وثيقة بالتاريخ لما تضمنته من مادة تاريخية أولية ، وتفسير لحوادث التاريخ ـ ويمكننا القول ان النمط القصصي الذي تميزت به الأسطورة كان الخيط الأول في لحمة التاريخ ، ويعكس طبيعة العلاقة الجدلية التي تربط الأسطورة بالتاريخ ، ويمنح التاريخ أهمية بوصفه عنصر من العناصر المكنونة للأسطورة ، وأداة اعتمدتها الأسطورة للإفصاح عن طبيعتها ، ومكوناتها و غاياتها ، وهيا و على الرغم من ان العلاقة وثيقة بين الأسطورة والتاريخ ، فأنها تبقى ، تعكس ثنائية متلازمة ينطبق عليها تعريف (العلاقة الجدلية) الذي يذهب الى انها علاقة بين ثنائيات متناقضة يستدعي بعضها بعض ـ فالأسطورة و التاريخ ، بينهما نوع من التعارض ، ولكنه ليس تعارضا مفرقا ، إذ ان هناك مستوى في العلاقة الوسيطة المشتركة بينهما ـ (13) و هذه العلاقة بين التاريخ و الأسطورة ، انما تسعى للكثف عن فكرة التطلع الإنساني الدائب الى الكثف عن بو اعث الأحداث التاريخية والر غبة في التتبؤ بسير ها والتحكم في مصير ها ، كما انها لا تخلو من محاولة للعثور على معنى لحياة الانسان ، و الوضوح ـ ان هذه الأساطير خلصت الى ان الالهة هي التي تتحكم في طبيعة الحوادث التي تمر بها البشرية عبر تاريخها ، " و الأسطورة كانت تتصور انجاز ات الالهة والكائنات العليا ومشيئتها ، على انهاور اء أعمال البشر ، وكانت الأساطير أحيانا تفسر حوادث التاريخ تفسيرا بطوليا ، من خلال دور انها حول مؤسس السلالات الحاكمة ، وحول ملوك الماضي السحيق ، وتأثير هم في توجيه مسار التاريخ من خلال حروبهم وحملاتهم العسكرية وأعمالهم الأخرى ، فكان سرجون الاكدي ، مثلا يصور من خلال تللك الأساطير ، كأنه

12 - ينظر : هرنشو ، علم التاريخ ، نر، عبد الحميد العبداوي ، (ب، ن) ، (ب،ط) ، القاهرة ، 1937 ، ص16 . 13 ـ ينظر : النجار ، جميل موسى ، فلسفة التاريخ ، مباحث نظرية ـ المكتبة العصرية ، ط1، بغداد ، 2007 ـ ص120 . 
ملك شبه الأسطوري ، خلال الألف الثاني قبل الميلاد . و أسطورة الطوفان عند السومريين و البابليين ، كانت تتضمن تفسير النهاية التاريخ ، من خلال تفسير التاريخ البشري ، و الحديث عن نهايته التي أدت إليها تصميم الالهة ومن ثم هلاك الجنس البشري" . (14 ) وبهذا فقد "وكانت الأسطورة في حضار ات الثرق القديم ، تمثل العلم البدائي أو التاريخ الأولي " . (15) ودلالة قدم الأسطورة ، ان الانسان لما بدأ يبحث عن اصل الأشياء عندئذ وجد أصلا أسطوريا ولم يجد أصلا تاريخيا ، كما وجد فيها المحاولات الأولى التي تبين الترتيب الزمني للأشياء و الأحداث ، ومعرفة انه ليس للزمن الأسطوري سياق محدد و انما هو زمن أزلي ، وبهذا المعنى يرى ديوارنت ، نقلا عن الملاح " ان تقسيم الأيام الى ماض وحاضر ومستقبل عمل من صنع

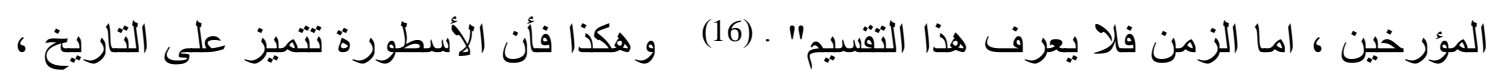
من وجهة نظر كولا ليفي شتراوس K.L.Shetraows من خلال زمنها غير المحدد ، اذ هي تفسير الماضي والحاضر والمستقبل ، في حين قد يقتصر التاريخ على حوادث حصلت في زمن غابر بعيد ، مما يمنح الأسطورة ، كما هو واضح ، شمولا و أصالة . فالأسطورة تهدف الى الكثف عن الثوابت ، ولا تسعى بشكل أساسي للتعرف على تتابع الحوادث ، مما جعلها تستمر في حياتها حتى انبثاق السرد التاريخي ، وتتعايش مع التاريخ ، في كثير من الأحيان ، من دون ان تتجاوز خصوصيته ، لان لكل منهما هدف خاص به ، وان تحديد الأهداف هذه جعل لكل منهما مرتكز اته التي ينطلق منها ، على الرغم من الأخذ في نظر الاعتبار ، إننا لا نهمل أبدا ان الأسطورة هي

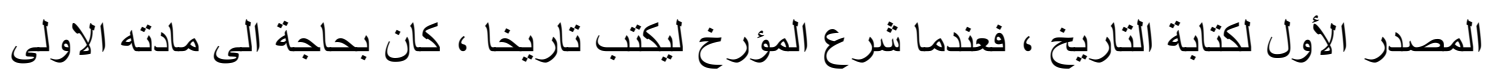
التي بستقي منها الأخبار عن العصور السالفة ، فما كان إمامه الى الأساطير القديمة ، التي ضمت بين أجو افها أخبار الاولين ـ و هكذا كان المؤرخ البابلي والمصري القديم ، يقدم أروع الصور الفنية

$$
14 \text { ـ الملاح ، هاثم يحيى ، المفصل في فلسفة التاريخ ، المصدر السابق ، ص126. }
$$

15 ـ ارنست ، كاسيرر، مدخل الى فلسفة الحضارة الانسانية . تر، إحسان عباس، دار الاندلس ، بيروت ، 1961، ص95. 16 - بنظر:الملاح ، هاشم يحيى ، واخرون ، دراسات في فلسفة التاريخ ، مديرية دار الكتب للطباعة والنشر ، (ب،ط) ،

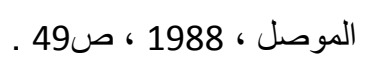


ذات الجمالية العالية ، متشعبا في أبعادها ، مستندا على أسطورته الممتلئة بأحداث أسلافه ، و التي

عبرت عن عمقا فكريا أصبح فيما بعد تأملا فلسفيا ، قامت عليه نظريات في التاريخ و الفلسفة. (17) وفي الثرق ايضا ، لا بد من الإشارة الى مساهمات الصينيين في هذا المجال ، إذ أولى الصينيون التاريخ السياسي للاولة عناية كبيرة ، فألفت في القرن السابع قبل الميلاد لجنة في العاصمة لتسجيل الأحداث المهمة لديهم وهي تشمل تاريخ اسر خاصة وملخصات حولية ومذكر ات مختلفة الأنواع وتراجم وسير ـ وقد لوحظ في هذه الكتابات انها لم ترتفع عن مستوى الطريقة الحولية في تدوين التاريخ ، كما ان المؤرخين الصينيين ، لم يضعوا هذه الكتابات موضع النقد

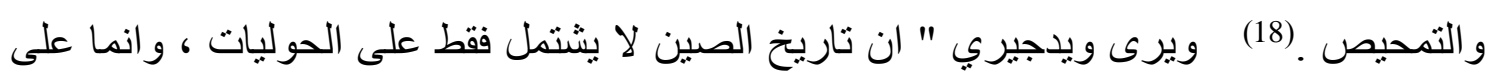
مجمو عة ضخمة من الوثائق ، ترجع الى عصور سحيقة في القدم ، لكن يندر التبصر فيها من ناحية طبيعة التاريخ ومغزاه ، لكن الغرب انبهر وتأثر أعمق التأثير بآثار الفن في الصين ، وبرسومها وبنقوشها على العاج، لكن ؟ المغزى الأساسي للتاريخ لدى الصينيون ، ينشأ على وفق وانغ يانغ مينغ ، على الاهتمام الوحيد والجدير بالاعتبار ، هو ان يبذل المرء وسعه ليصير حكيما ، اي ليحقق الثخصية الأخلاقية و المسلك الاجتماعي الذي يوصي به ، المثل الأعلى الكونفوشي ـ ولا يعني هذا حياة تأملية (كما يعتقد بان البوذيين يعلمونه ) و انما حياة فاعلة في الوظيفة المنوطة بكل فرد " . (19) المطلب الثاني : التاريخ عند اليونان والرومان .

" لقد شغف الاغريق بالبحث التاريخي ، أو بما يسمونه باليونانية Istoria أي تاريخها حتى برزوا عن غير هم في هذا الميدان ـ فكتب هكتيوس Hecateus في القرن السادس ق.م عن اصل الشعب الإغريقي ـ كما كتب هيرودوتس Herodotus الذي بلقب بأبى التاريخ في القرن

17 - ينظر : النجار ، جميل موسى ، فلسفة التاريخ ، المصدر السابق ، 124 . 18- ينظر : ادهم ، علي ، تاريخ التاريخ ، (ب،ن) ، (ب،ط)، القاهرة ، 1977 ، ص14-15. 19 ـ ويدجيري ، ج. البان ، الدذاهب الكبرى في التاريخ ، من كونفوشيوس الى توينبي ، تر، ذوقان قرقوط ، دار القلم ، ط2، بيروت ، 1979، صجيري ج. 
الخامس ق.م ، عن النزاع بين الاغريق والفرس ، وبعده كتب ثوكوديديس Thucydides، عن حرب البلويونيز بين أثنينا و إسبارطة " ـ (20)

وكان التدوين التاريخي عند الاغريق قد اتخذ شكل الأسلوب الملحمي ـ ويذكر في هذا المجال الثاعر الإغريقي هو ميروس ، بصفته ملهما لامته ، وقد اخذ عنه المؤرخون تمجيد البطولة وروح الكفاح الذي يدفع الانسان الى التفوق على من حوله ـ و وعلى الرغم من امتزاج التاريخ بالأسطورة في بواكير التدوين التاريخي عند الاغريق ، الا ان السمة العقلانية تبلورت من خلال رؤية ، تميز بها المؤرخ الإغريقي عن المؤرخ التوراتي ، فنجد ان الكاتب الإغريقي اعتمد على تصور مسار الأحداث في ضوء القول بتحزب الالهة للإنسان ومسؤولية الأخير عن الأحداث والوقائع التاريخية

ـ وبهذا اخذ التاريخ بعدا إنسانيا جديدا على بد الإغريق . (21)

و الدليل على ذلك ، ان هوميروس، صور لنا من خلال الإلياذة ، ان الإله ( زوس ) بأنه لم يكن يمتلك القوة الكافية ، مما يدلل لنا على مواقف يقوم بها البشر ، وليس الآلهة التي ينبغي لها ان تتصف بقوى قاهرة جبارة ، بعيدة عن العو اطف و النزعات الثهوية التي يتصف بها البشر ـ وهذا يثير إلى ان الأساطير التي تدور حول الآلهة ، ان هي إلا رؤية إنسانية قدمها الإنسان ، تتحدث عن آلهة تنشابه من حيث التصر فات ، وبعض الصفات ـ متخذة لها صور ا ورموز ا وأفكار ا تتطبق على الثر تماما . (22) ع (2)

بيد ان الباحث ، لا يرى في دراسة تاريخ اليونان ، على انه يستعرض سردا لأحداث تاريخية تدور رحاها حول قصص سردية لوقائع حربية ، أو دراسة أخبار ملوك أو أباطرة ، حكمو اوز ال حكمه ، فهذا لا يثبع حاجة الباحث عن تاريخ حضارة مثل حضارة اليونان ، أثرت في الحضار ات الأخرى ، وقبل منها ، هي كذلك قد نأثرت بحضار ات الثرق ، فأن التاريخ اليوناني ،

20 Collingwood. R.G. ; The Idea of History (Oxford. 1946.pp.33-36.

$$
21 \text { ـ ينظر : الملاح ، هاثم يحيى ، واخرون ، دراسات في فلسفة التاريخ ، المصدر السابق ، ص32 . }
$$

22 ـ ينظر : المخزومي، عادل ، مدخل الى فلسفة التاريخ ، مؤسسة مصر مرتضى للكتاب العر اقي ،ط2 ، القاهرة ،2010 
كانت تعلو سمائه حركة عقلية ذات طابع تأملي ، امتزجت بالأسطورة التي طوعها مفكريهم ، و التي احتضنت ماضيهح بكل تداخلاته ، و الدليل في ذلك ان هذه الحركة العقلية في التاريخ اليوناني ، انها أنتجت طابعا جديدا في التفكير اليوناني ، تميز في انه ترجم ماهو ليس عقلي الى محاولة عقلنته ـ. " فنما التفكير وتطور نحو الاستفادة القصوى من الظروف الو اقعية التي يحياها الإنسان فتوجه الفكر نحو الاهتمام بالوجود الطبيعي ، من خلال نهج سبيل التفكير القائم على الملاحظة. و التحليل العقلي والابتعاد رويدا عن الارتكاز إلى الفكر الأسطوري على الرغم من ان التفكير بالنسبة للإنسان كان نشاطا شاقا وبعيدا عن النهج الطبيعي " . (23) و هذا أنتج فكر ا اختلطت فيه الأسطورة بالاستنتاجات العقلية المنبعثة من التفكير في الواقع الموضوعي المادي الذي يحياه الإنسان وهكا جاءت النتاجات الأدبية المبدعة مع الإلياذة و الاوذيسة لهوميروس ، في الثلث الأول من الألف الأول قبل الميلاد ، لتعبر خير تعبير عن هذا الاختلاطوقد كونت أول إبداعات الفكر اليوناني في أسيا الصغرى (24) هذا أدى الى حدوث أول تمرد على الطبيعة الأسطورية للتاريخ ، نادت به مدرسة هوميروس ، الذي ادخل في العمل التاريخي بعدين منهجيين : الأول : تم تعريفه بـ (العقلانية ) وهو الالتز ام بتدوين الأحداث بحسب و اقعها ، بعيدا عن الأساطير و الخر افات.

23 ـ نوينبي ،ارنولد ، الفكر التاريخي عند الإغريق ،ترجمة لمعي المطيعي ، مراجعة محمد صقر خفاجة ، الهيأة المصرية

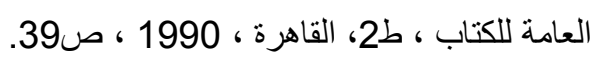

24 - ينظر : عبد الحي،عر،،الفكر السياسي في العصور القديمة.مجد المؤسسة الجامعية للاراسات والنشر والتوزيع ،2018

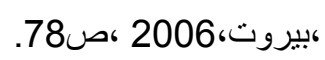


و الثاني : (العالمية) و المراد بها : الاهتمام بتواريخ الأمم الأخرى وتدوينه الى جنب التاريخ الخاص.(25) و اذا كان ثمة علامة مضيئة في قدم الفكر التاريخي عند اليونان ، هي ما ابدعه هيرودوتس في كتابه (التاريخ ) و الذي تبنى فيه خصائص منهجية جديدة في الكتابة التاريخية . وتميز اسلوباه بالكتابة بثلاثة مزايا رئيسة هي : اولا : اهتمامه بتاريخ الأشخاص وحفظ المآثر. ثانيا : تدوين الحوادث او القصص التاريخية ، طبقا للو اقع ، بعيدا عن الأسطورة . ثالثا : الاهتمام بالتاريخ العالمي ، وتجاوز التاريخ القومي والوطني المجنز أ . وييقى كتابه في التاريخ أهم المر اجع لمعرفة أخبار الأمم القديمة .وهو عبارة عن تسعة كتب في مجلد واحد اسماه ( ايستوريا ) وهي كلمة يونانية تعني البحث و الاستفسار من اجل الفهم ـ (26) ويذهب ارنولد توينبي ، في أهية هيرودوتس ، الى إن " نتائج أبحاثه لها هدفان ،احدهما إنقاذ تاريخ الجنس البثري من النسيان ، ثم اثبات ان الأعمال الرائعة التي اضطلع بها الهيليون و الثرقيون سوف تتمتع بما هي أهل له من شهرة - خاصة تللك التي أدت الى صدام فيما بينها " (27) و المتتبع لحركة العقل في الفكر التاريخي اليوناني بامكانه ان يلاحظ ، ان عملية الوجود كانت تخضع لدورة تاريخية ، و هذا ماستدعى المفكرين الأو ائل من الفلاسفة ان يتأملو ا في طبيعة لئه خلقهم ، وهذا ما عبر عنه هرقلبطس ، في قوله ، كما صرح به ويدجيري ، " ان جميع الأمور

25 - ينظر : عبد الحميد ، صائب ، علم التاريخ ومناهج المؤرخين ـ مركز الغدير للاراسات الإسلامية ، ط1، بيروت ، 2001 ، ص19 . ש.

26 - ينظر : قاسم ، عبده قاسم ، تطور مناهج البحث في الدراسات التاريخية . ، مجلة عالم الفكر ، المجلد 20 ، العدد 1 ، ص198-198

27 ـ ينظر : توينبي ، ارنولد ، الفكر التاريخي عند الاغريق ـ تر ، لمعي المطيعي ، مراجعة ، محمد صقر خفاجة ، الهيئة

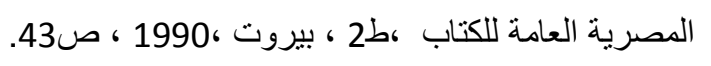


الإنسانية والالهية تنشأ بالتبادل من الأعلى الى الأدنى ومن الأدنى الى الأعلى " ، في حين نرى ان بارمنيدس ، الذي ذهب الى ان التاريخ لا بتكون إلا من تغير ات عارضة من صميم حقيقة وحيدة . و امبادوقلس ، أكد على ان الر أي كان يرمز بالحب و الحقد الى مبدأي الحقيقة الفعالين ، وان هذين المبدأين يفرضان نفسيها بالتناوب ، لكن كانت الدورة تحسم نفسها ، ويتحول احدهما في الأخر

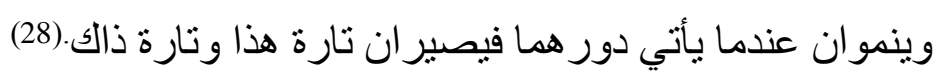

و هذا أفلاطون ، قد عد الزمان بمعنى( الدهر) تارة وبمعنى الدورة الفلكية المحسوبة بمقياس السنة الكبرى تارة أخرى ، حين وظف المفهوم البابلي للرقم ( 60) ومعادلة (الشباب) الدوري ، في تحديد (مدة الدورة وهي ( 10800) سنة كحاصل ضرب ( 30 الى 360 ) ـ لتؤشر لنا ( العصر الذهبي ) الذي عاثته البشرية في الماضي السحيق . وان اختصت محاورة طيماوس ، في تقديم تفسير علمي ، للزمان و الفلك ، لكن أفلاطون ( على رأي Barnes يقدم محاولة لتفسير التاريخ جاءت موزعة بين فكرة ( الماضي الذهبي ) و( فكرة النكوص ) التي تحدث عنها هزيود ـ اما أرسطو فقد عد الزمان مقياس حركة الأشياء النازعة الى كمالاتها على هذه الأرض ، حتى تبدو فيه الأحداث ، مدفو عة وراء غاياتها على أساس فكرتي ( التقدم ) و (التأخر ) الفلسفيتين ـ وكاد يمس القضية التاريخية ، مسا مباشر ا وهو يبحث في الإنسان والطبيعة . فكل شيء عنده يتغير في زمان وصيرورة ، بعد ان جعل الزمان مشابه للأجيال المتعاقبة ، من الناس ، ليس فيها انقطاع ، ولكنها اذا ولدت بلا انقطاع فأنها تهلك بلا انقطاع أيضا ، أنها جريان زئبقي لا يعرف إلا بالحوادث الجسيمة التي اضطرب فيها أرسطو، بين القول بالعامل الفلكي ( الكواكب ) وتأثثير ها في التاريخ وبين القول بالقطيعة بين الحو ادث الأرضية والأسباب العلوية ، ويبدو ان مسار التاريخ موجه في جوهره توجيها معينا - غائيا ، بسبب تطبيقه قو اعد بيولوجية ، على تكوينات تاريخية ، تعكس سعي البشر لتحقيق أهدافهم . (29) 
وتمثل الوعي التاريخي عند الرومان ، من خلال تدوينهم الأحداث التاريخية وفق اسلوب الحوليات ، اعتمادا على السجلات الرسمية ، التي كانت تعني بها المؤسسات الدينية ، وتناولت وقائع الانتصار ات و الهز ائم وتعاقب الحكام والأحداث المهمة الأخرى ، وبخاصة تللك التي ترتبط بالمعجزات والاحتفالات الدينية ـ وكان من ابرز ملامح فهم التاريخ عندهم هو استثمار التاريخ تربويا للأغر اض السياسية . كما عد المؤرخ نفسه صاحب رسالة وطنية ، ودونتها الحقيقة التي

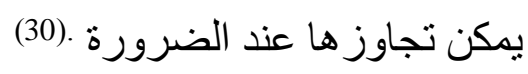
ونلحظ ان بوليب ، الذي تولى تأليف ما كان بمثل في نظره ، ( تاريخا شاملا ) وللوصول الى نظرة دقيقة في التاريخ ، كان يرى انه ينبخي در استه جملة ، وفي كل ما يمكن ان يؤول اليه ـ و أكثر ما كان يهمه هو ان يدرس كيف اخضع الرومان جميع العالم المسكون تقريبا لحكومتهم الوحيدة ، وكان يعطي تسلسل الأخبار التاريخية قيمة بر اغماتية . فيقول : كما أوردها ويدجيري " ما من شيء أصلح لتقويم سلوك الناس من معرفة الماضي " وكانت وجهة نظره هي ما نز اه البصيرة العامة التي تتبذ الأوهام او تزدريها ـ و هكذا لم تكن الصدفة تظهر له في ملامح الـهة الصدفة ، التي يحبها كثير من الرومان ـ ولكن الصدفة هي (طبيعة الأثياء ) الظروف الواقعية في عصر معين ومكان معين ـ و هذه الظروف تكون ملائمة او غير ملائمة ، وفي حالة كونها غير ملائمة ، فأن الناس يستطيعون معارضتها وأحيانا يستطيعون معاكسة آثار ها ـ وكان يعتبر سيطرة الرومان الشاملة مرسومة من الله ـ فأن هذه السلطة على العالم قد حصل عليها الرومان بفضل ثربيتهم

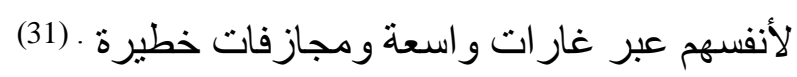

وكانت أر اء بوليب، و اضحة في تقدم علم التاريخ ، و التي يمكن ملاحظتها من خلال تشجيعه للأساليب المثالية للار اسة المنهجية السليمة . فضلا عن ذلك فأنه أكد على أهمية معرفة الجغر افيا

30 - ينظر : هورس ، جوزف ، قيمـة التساريخ ، تـر ، الثيخ نسيب وهبـة الخـازن ،(ب،ن)، (ب،ط)،بيروت ،1964 ، ص29-27. 31 ـ ينظر : ويدجيري ، ج، ألبان ، المذاهب الكبرى في التاريخ ، المصدر السابق ، ص91. 
و الطبو غر افيا للمؤر خ وأهميتها في در اسة التاريخ ، و هذا ما تبناه لاحقا مونتسكيو (32) في تفسيره الجغر افي للتاريخ والحتمية الجغر افية . كذلك فأنه ، يعد ، رائد استقر اء خلفية الأحداث وربطها بمجريات الحدث ونتائجه ، فبدون هذا الربط سنكون عملية فهم التاريخ ، مجرد فهم أدبي خالي من العبرة ، و لا مستقبل لنتائجها ، على الرغم من استمتاع الآذان وانتعاش الأذهان بها . (33) و هذا الفهم الأدبي ، شكل تصورا جديدا للوعي التاريخي عند الرومان ، اخذ بعدا جديدا لم يكن معهودا في تاريخهح ، من ناحية الاعتماد على المؤثزات البلاغية ـ و هذا ما عده ( شايلا ) إضعاف للحقيقة التاريخية في مسار التاريخ عندهم ، لان المؤثرات البلاغية تؤدي الى إهمال الربط بين أسباب الأحداث او مقدماتها ونتائجها ، و هذا الإهمال إنما حكمته ظروف الاهتمام بالثكل البلاغي . وبالإمكان بهذا الصدد ان نشير الى ان شيشرون ، وهو أعظ خطباء روما قد عبر عن هذا الاتجاه حين عرف التاريخ بأنه ( واجب الخطباء المثمر ومن شأن الخطباء أساسا ) ـ و هذا يحيلنا الى القول بأن المناخات الفكرية لذلك العصر كانت قد سادتها روح الخطابة ، كما برز في اليونان السفسطائيون ومحاولتهم إثناعة فن البيان ، واعتباره أساس الحقيقة ومصدر ها ـ ومن الجلي ، ان الرومان كانوا قد تأثروا في الكثير من مظاهر الحضارة اليونانية ، فربما كان انتشار الآداب و الفنون في اليونان قد امتد هو الأخر كمظهر من مظاهر التاريخ اليوناني الى الرومان .(34)

32 - هو شارل دي سوكوندا مونتسكيو ، يعد مفكر اوسياسيا واجتماعيا وفيلسوفا ومؤرخا ، انحدر من اسرة عريقة ونبيلة ، ولد في قصر

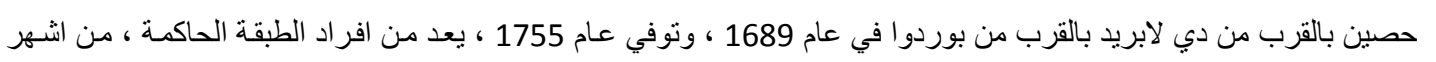

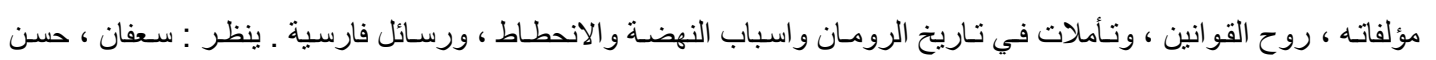

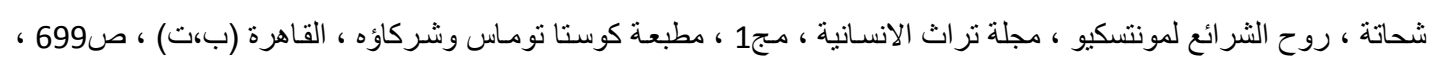

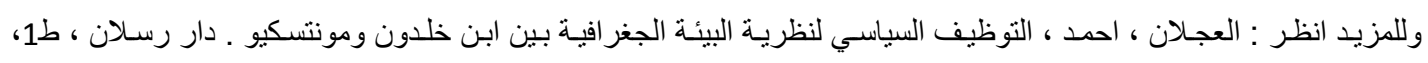

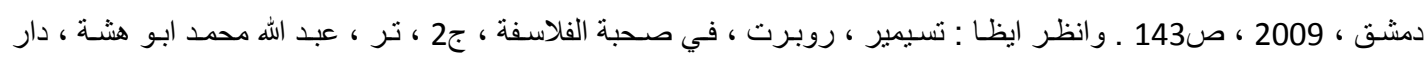

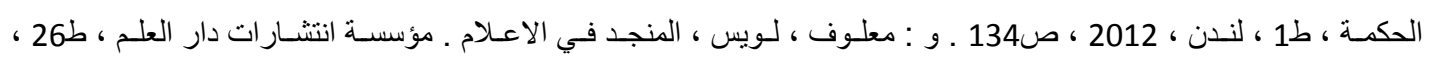

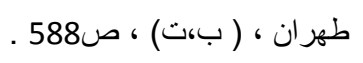

33 ـ ينظر : السعيدي ، حميد خلف ، دروس في فلسفة التاريخ . دار أبجد ، (ب،ط) ، بغداد ، 2007 ، 21. 34 - ينظر : شايلد ، جوردن ، التاريخ ، تر ، عدلي برسوم عبد الملك ، (ب،ن) ، (ب،ط) ، القاهرة ، 1958، ص54. 
بيد ان هذا لا يعني إنكارنا لجهود الرومان الساعية لإقامة الدليل على أصالة فكر هم التاريخي ، وان فكر هم المعني بالتاريخ ، كان يروقه ان يذكر ( وقائع ) مستخلصة من مجرى الحوادث في وضوح من الحدود ـ وان المؤرخين الرومان قد تمكنوا من إيجاد علاقات بين الأساطير الدينية و الإمكانات البشرية ، تلك الأساطير التي كانوا يملكونها منذ وجودهم ، و التي أعطوها مظهرا تاريخيا حقا ، حتى انهم جسدوها في التاريخ ان صح التعبير ، بينما نرى ان الأمر مختلف عند غير هم من الشعوب ، الذين اخرجوا الحوادث البشرية من نطاقها وحملو ها الى صعيد عجيب خارج حدود الطبيعة . وقد عمد الرومان ، منذ مطلع وجودهم الدولي ، الى العناية بالتاريخ فأسسوا في روما ( مخازن وثائق ) عهدوا بالعناية بشأنها الى مؤسسات رهبانية أسموها كليات ـ ومن هذه الكليات كانت تصدر اليومية ـ الروزنامة ـ المشتملة على (أيام الثؤم ) و(أيام الفأل) تبعا لما كانت

تذكر هم به تأريخ الأيام من حو ادث مشؤومة او أخرى سعيدة . (35)

وبهذا يكون للتاريخ عند الرومان شخصية مركزية ، فكانت روما تللك الثخصية ، اذ انها سبب تاريخهم نفسه ـ ومنذ عهدهم أصبحت كتابة التاريخ ، قيامه بوظيفة من وظائف الدولة ، لأنه قد أعطى لكل مؤرخ ان يؤمن لشعبه عناوين نصره ، وكنزه من الحكمة السياسية . ولا شك ان هذا الاهتمام النفعي استطاع ان يظر بروح البحث الحقيقية ، وهذا التوق الى المعرفة الذي لا بد منه بكل مؤرخ حقيقي ـ وهكذا صوبت روما كل انتباهها الى ذاتها ، فاستطاعت ان تدمر الشعوب واحدا بعد الآخر ، غير مبقية منها إلا أثر ا بسيطا في حينها . (36)

وفي إطار الوعي التاريخي أيضا ، و الذي يقابل فلسفة التاريخ ، قبل ان يصطلح هذا الاسم ـ يبدو ان سيطرة الفكر الديني المسيحي لم تكن وبالا محظا في مجملها على التاريخ ، ذلك ان الافق الفكري الضيق الذي هيمن على عملية الوعي التاريخي ، من خلال كتابة التاريخ أواخر العصر الروماني ، ووظفها لإغر اض محددة ، كان يتسم ، في الوقت نفسه ، بنظرة ذات أفق أكثر رحابة

35 - ينظر : هورس ، جوزف ، قيمة التاريخ ـ المصدر السابق ، ص30. 36 ـ ينظر: يزبك ، قاسم ، التاريخ ومنهج البحث التاريخي ـ دار الفكر اللبناني ، ط1، بيروت ، 1990، 20-21. 
تجاه التاريخ مستمدة في إطار ها العام من المبادئ الأساسية للايانة السماوية - كالخالق ومفهوم الحياة على الأرض و البعث و الحساب ـ رؤيتها لمسيرة التاريخ البشري ـ وقد تمثلت هذه النظرة بما يمكن ان نعده (فلسفة التاريخ ) تستند الى اصول المسيحية والفكر المسيحي معا ، صاغها القديس أوغسطين 354- 430 م ، اشهر أباء الكنيسة اللاتينية في كتابه (مدينة الله) ، وحاول فيها ان يتأمل مسيرة التاريخ البشري على وفق الدين وتصورات الفكر الديني ليفسر الواقع ويستشرف (37). المستقبل ، و هو يقابل فكرة التنبؤ التاريخي في فلسفة التاريخ المبحث الثاني : الظهور وتظور المصطلح . المطلب الاول : ظهور فلسفة التاريخ • ملامح الفكر التاريخي ، وتطوره على وفق ما تم طرحه ، لدى مفكري حضار ات الثرق القديم ، وحضارة اليونان و الرومان ، ما زال قبعا على وجهه ، ولم يتسنى له النظر الى الأفق البعيد ، رغم اعتباره يمثل نقلة نوعية في مناخات الفكر العام ، وتطوره ومساهمته في بلورة الفكر الفلسفي ، فما ز الت الأسطورة تلقي بظلالها في معظم النصوص التاريخية ، ولم تنفك الحركة الأدبية عن إضفاء الطابع البلاغي في رؤية التاريخ ، مما أدى الى تشكيل صورة ضبابية تسمو على الواقعية ، و هذه الصورة انما هي ناجمة عن ضياع ماهو طبيعي ، من ما هو ليس طبيعي ، فاختلطت فكرنين ، وضاع المسار التاريخي الذي أدى الى فقدان الغاية ، ففكرة التاريخ ذو المصدر الأسطوري حاضرة في الأذهان ، تقابلها ظهور الديانات ، و التي هي الأخرى قدمت مفهوما جديدا عن التاريخ ـ إلا ان الإدراك التاريخي لدى العقل القديم ، ضاع بين هاتين الفكرتين ـ لكن ؟ ماقدمه كل من القديس

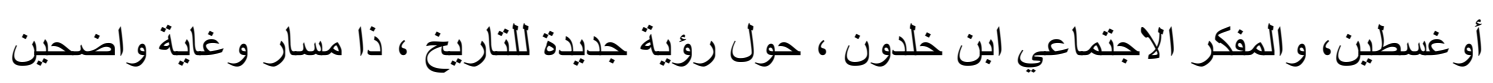
، يتيحان لنا ، تجسيد فكرة ظهور فلسفة التاريخ ، كمدخل لهذا المطلب ، موضوع الدر اسة .

37 - ينظر : النجار، جميل موسى ، فلسفة التاريخ ،المصدر السابق ، 64-65. 
أ - القديس أوغسطين . (38)

تمثل نظرية (العناية الإلهية ) ، عند القديس أوغسطين مدخل لدراسة الفكر التاريخي ، والذي تطور في عصر التنوير الى (فلسفة التاريخ ) ، وهو أول من كتب في فلسفة التاريخ ، حيث ألف كتابه (مدينة الله) على الرغم من انه لم يكن مؤلفا او فيلسوفا ، و انه كان رجل لاهوت ، وقد عرض آرائه حول مسيرة التاريخ وغايته ، في إطار تصور اته الدينية وتفسيراته للكتاب المقدس عند المسيحيين .(39) وهو يرى ، ان النبي ، هو الذي سيجلب الطمأنينة للمظلومين والمبتلين ، بإعلان حكم الله على الو اقع بالهلاك ، و إعلان ما سيحل محله " أنا يوحنا رأيت المدينة المقدة ، أورشليم الجديدة نازلة من السماء من عند الله " ، " ها هو مسكن الله والناس : يسكن معهم ويكونون لله شعوبا " . (40) على ان اهم ما أتت به المسيحية الى التاريخ ، هو فكرة المساواة بين سائر الشعوب المسكونة ، اذ احلت في العهد الجديد المدينة الانسانية العالمية محل شعب الله المختار في هذا العهر القديم ، وصسار البشر اجمعين شركاء في مدينة الله دون تمبيز بين لون او جنس ، طالما ان المعيار الوحيد هو الصلاح والتقوى ، ولقد كان خير من عبر عن هذا الاتجاه العالمي في تدوين التاريخ وفلسفته ، المؤرخ الثهير يوسبيوس القيساري ، او ائل القرن الرابع الميلادي ـ اذ حاول ان يكتب تاريخ للعالم كله منذ البداية تمهيدا لحجر الزاوية عنده الا هو مولد السيد المسيح . (41)

38 - القديس اوغسطين ، ولد عام 354 ومات عام 431 ، و هو فيلسوف من اصل جزائري ، ونجد ان معنى اسمه هو الملك الصغير ، عاش شابا مضطربا ، ثم اهتدى على مو اعظ القديس امبروسيوس ، وحاول التوفيق بين العقل والايمان وقاوم البدع ـ للمزيد انظر : عبد زيد ، عامر ، التأويل اللاهوتي للتاريخ عند او غسطين . ضمن كتاب فلسفة التاريخ جدل البداية و النهاية و العود الدائم ـ الرابطة العربية الاكاديمية للفلسفة ، اشر اف وتحقيق علي عبود المحمداوي ، ، ابن النديم للنشر و التوزيع ، دار الروافد الثقافية ـ ناثـرون ،

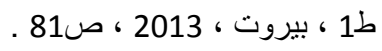

39 ـ ينظر : الملاح ، هاثم يحيى ، المفصل في فلسفة التاريخ ، المصدر السابق ، ص214. 40 ـ الكتاب المقس ، العهد الجديد ، الإصدار الرابع ، (ب،ن) ، الإصدار الرابع ، ط30، (ب،م) ،1993، ص404. 41 ـ عبيد ، اسحاق ، معرفة الماضي من هيرودوت الى توينبي ـ دار المعارف ، ط1 ، القاهرة ، 1981، ص8 . 
" و أو غسطين يرفض وجود الصدفة في أحداث التاريخ لان كل شيء مقدر من قبل العناية الإلهية ، كما ان الإرادة الإلهية لا تقبدها قوانين الضرورة في الحياة ـ وهكذا فأن سير التاريخ الأرضي مسير ا ومحكوما من الله وفقا لما يحلو له " .42)

و هذا يشير ، إلا انه يرى ، ان التاريخ يخضع لإر ادة الله ، وان المصادفة ، لا وجود لها في الكون ، فلا شيء يوجد في هذا الكون مصادفة ، لان الإيمان بوجود المصادفة يقود الى العبث و الفوضى و الاضطر اب ، ولو لا تدخل الله في توجيه مسار حياة الإنسان ، لما عمل الإنسان خير ا من التاريخ ، ولأصبح التاريخ دون غاية ، ويرى أوغسطين ، ان الثر دخل العالم بمعصية ادم ، وان الإنسان ذو نزعتين ، الأولى نزعة حب الذات الى حد الاستهانة بالهه ، و الثانية نزعة حب الله الى حد الاستهانة بالذات ، و هذه الرؤية انما تمثل اتجاها جديدا في الرؤية الى الله ، تتمثل في تحليل نوازع الإنسان السايكولوجية ، بعد ان عرفناها ، قبل أوغسطين تمثل املاءات الطبيعة ، التي تفرض صيرورتها على تكوين فكرة التاريخ ، وحتى الإنسان عندما كان يريد ان يتأمل أسرار الكون ، لا يجد غير

بواعث الطبيعة لكي يستشهد بها .43)

من هنا حاول أو غسطين ، إرساء معالم جديدة لنظرية العناية الإلهية ، على انها نوع جديد لفرض نمط ديني على خط سير الحركة التاريخية ، بوصفها هي التي تسير أحداث التاريخ الى غايتها ، وذلك في كتابه (مدينة الله) التي قامت فكرته على ان التاريخ يدور حول كل من المؤقت والابدي ، أي الدائم ، فاله ابدي ، و هو خالق الزمن ، و لا يجوز فهم الأبدي و لا تصنيفه زمنيا . (44) و التاريخ عنده يسير في خط مستقيم من ادم الى مملكة الله النهائية ، منتهى المؤمنين ، وهو يرفض فكرة العود الأبدي ، لان المسيح صلب مرة ، وفدى البشر مرة واحدة ، وما لله بداية ، لله نهاية ، يقول : ( بدأ الله خلق الإنسان و العالم ) على انه فعل جديد ومن دون أي تغيير في الغرض

$$
42 \text { - ويدجيري ،ج، ألبان ، المذاهب الكبرى في التاريخ ، المصدر السابق ، ص148. }
$$

43 - ينظر : الدليمي ، حامد حمزه حمد ، فلسفة التاريخ و الحضارة ، دار الطيف ، (ب،ط)، واسط ، 2004، ص133-134. 44 ـ ينظر : الثيخ ،غنمي ، فلسفة التاريخ ،دار الثقافة والنشر و التوزيع ، (ب،ط)، القاهرة ، (ب،ت)، 78. 
و الخطة الإلهية ، بل وفقا لخطة الأزلية وسينتهي الحال اليه لقبول الناس او رفضهم في مدينة الله بحسب إيمانهم . (45) ومن هنا قسم التاريخ البشري الى سبعة أقسام :

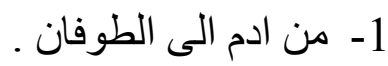

$$
\begin{aligned}
& \text { 2- من الطوفان الى إبراهيم . } \\
& \text { 3- من إبر اهيم الى داوود . } \\
& \text { 4- من داوود الى الأسر البابلي . } \\
& \text { 5- من الأسر الى ميلاد المسيح . } \\
& \text { 6- من ميلاد المسيح الى أوغسطين (العصر الحاضر). }
\end{aligned}
$$

7- نهاية العالم يوم ( الذي سيستريح فيه الله كما حدث في يوم السابع ، وسيمنحنا الراحة في

$$
\text { ذاته).(46) }
$$

و هنا تجدر الإشارة ، الى ان تقسيمه التاريخي هذا ، قد ارتبط من ناحية التاريخ بالأخلاق ، بالإضافة الى صبغته الدينية ، فهو قد ذهب الى ان الشر قد دخل العالم بمعصبة ادم ، و هذه الإشارة انما تصنف تحت فئة الأخلاق المعيارية ، وقد أخذت بعدا تاريخيا بنى أوغسطين ، تصنيفه التاريخي على أساسه . ولقد انتهى من خلال تفسيره الديني للتاريخ الى ان السلطة النهائية في قيادة المجتمع في المجالين الديني والسياسي ينبغي ان توضع في يد الكنيسة .فلا عجب ان غدا تفسيره للتاريخ هو التفسير 45 ـ الالوسي ، حسام الدين ، الزمان في الفكر الديني والفلسفي القديم ، المؤسسة العربية للاراسات و النشر ، (ب،ط)،

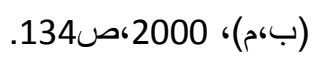

46 ـ المزوري ، زاهدة محمد الثيخ طه ، اركولوجيا فلسفة التاريخ ،المسار التطوري لفلسفة التاريخ .دار مكتبة البصائر

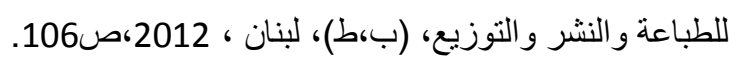


الرسمي للكنيسة على مدى أكثر من ألف سنة . ولم يتعرض هذا التفسير للنقد والمر اجعة إلا مع بدايات عصر النهضة في أوربا . (47)

ويمكن القول ، انه قدم أول نظرية في فلسفة التاريخ تستند الى أسس لاهوتية مسيحية ، فظهرت منذ ذلك الحين تفسيرات للتاريخ وتصور ات مختلفة لكيفية مسيرته تستند الى العقائد المسيحية في المقام الأول ـ وتركت هذه التفسيرات أثر ها في الفكر الغربي طوال القرون الوسطى ، وحدَت من الاهتمام بالتاريخ والتدوين التاريخي الذي كان يقتصر في تللك الحقبة على (حوليات) و(تواريخ) لاتهنم غالبا بسوى تاريخ الكنيسة ورجال الدين وخو ارق الطبيعة . (48)

ب - ابن خلاون . أتى ابن خلدون بعلم جديد ، لم يسبقه احد إليه هو (فلسفة التاريخ) ، وكان يدرك ذللك تماما ؟ وفلسفة التاريخ التي لم تظهر في أوربا إلا بعد ذلك بعدة قرون .

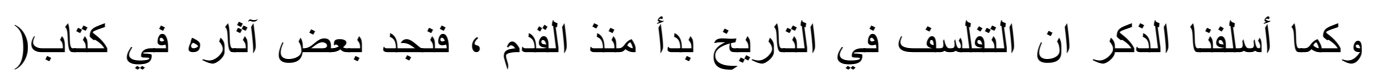
السياسة ) لأرسطو ، وكتاب (الجمهورية ) لأفلاطون ، أما التعبير نفسه فلم يستحدث إلا في القرن الثامن عشر . (49) وتقوم دراسة ابن خلدون ، للتاريخ من خلال اهتمامه في دراسة الاجتماع الإنساني الذي هو عمر ان العالم ، وما يعرض لطبيعة ذلك العمران من الأحوال .واعتبر هذه الدراسة هي المعول عليها لمعرفة التاريخ و أحداثه الماضية ، لبيان حضارة الأمة ، و معرفة كل ما يتصل بها من مفاهيم وقو انين وسنن كانت مؤثرة في و لادتها ونمو ها ونهضنها ، ومن ثم ضعفها وتحللها و انهيار ها . ضمن هذا المنهج وجدنا ابن خلدون ، قد اختلف عن المؤرخين الآخرين الذين اهتموا لأثر الفرد و البطل ، بينما كان هو مهتما لتاريخ العمران الذي عنده هو الأساس في رقي الحضار ات وسقوطها

47 ـ الملاح ، هانثم يحيى ، المفصل في فلسفة التاريخ ، المصدر السابق ، ص97. 48 - ينظر :النجار ،جميل موسى ، فلسفة التاريخ ـ الدصدر السابق ، ص146. 49 ـ الخضيري ، زينب محمود ، فلسفة التاريخ عند ابن خلدون ، دار التنوير للطباعة والنشر والتوزيع ، (ب،ط)، بيروت ، 
• و هذا التوجه في فكره ،قد جعل الباحثون و المؤرخون العقلانيون يعدونه ، قد سبق المؤرخين الأو ائل ـ وتفوق عليهم و على جميع الذين جاءوا بعده بعدة قرون على المستوى العالمي ـ وهذه النظرة الثاملة في موضوع التاريخ ، من النظرات الخاصة بأسم ما يسمى عادة بأسم (تاريخ الحضارة) (50) ويرى، ويدجيري ان " ابن خلدون يمنح أحيانا ، لقب مؤسس علم التاريخ ، لأنه كان يؤكد ان التاريخ هو جملة من المعارف النوعية ، يشكل موضو عها جماع الظواهر الاجتماعية المسجلة في التاريخ الحقيقي كما يشكله البحث في العوامل التي ما زالت تمارس فعلها فيه " . ويهذف التاريخ الى ان يستخلص من ذلك ما يصل الأسباب بمعلو لاتها وكذلك المركبات الطبيعية و النفسية . كما ان التاريخ ليس ، وفقا لرأيه ، رواية بسيطة للحوادث ولكنه وصف للعلاقات (51) الاجتماعية (51) و اثبت ابن خلدون ثلاث قضايا تشكل الدعائم الأساسية لفلسفة التاريخ : أولها : ان التاريخ علم من العلوم ، تعتمد في در استه مناهج العلوم الطبيعية ، يستخلص منها قوانين يمكن تعميمها على الظواهر التاريخية . و الثانية : ان التاريخ، من هذه الناحية ، يعد فر عا من فروع الفلسفة . و الثالثة : و هي الجديدة حتى ألان ، و التي لم يسبق إليها أيضا ، وهي تصوره الو اضح للتاريخ الكلي ، وتمبيزه عن تاريخ الأمم ـ و لا شك ان فلسفة التاريخ إنما تعني بالتاريخ الكلي ، الذي افرغ له ابن خلدون ، مقدمته بتمامها ، و هكذا اقام منذ البدء ما تقوم عليه فلسفة التاريخ من أسس ، فأستطاع ان

50 ـ ينظر : المخزومي ، عادل ، مدخل إلى فلسفة التاريخ ، المصدر السابق ،ص148-149. 51 - ينظر : ويدجيري ، ج، ألبان. المذاهب الكبرى في التاريخ .المصدر السابق ، ص134. وينظر : النشار ،مصطفى

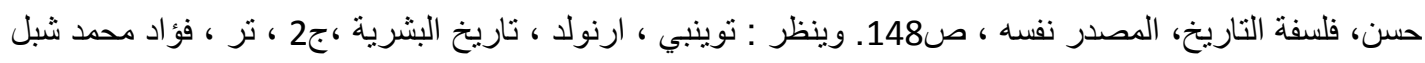

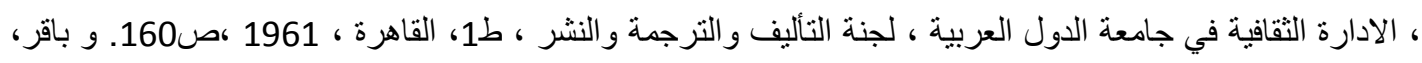

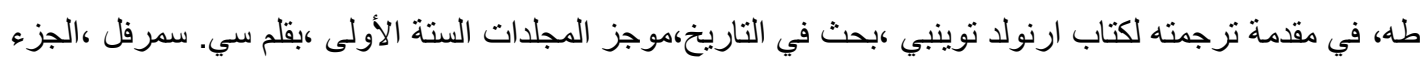

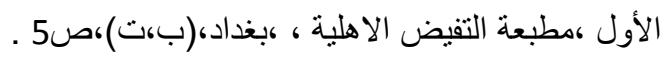




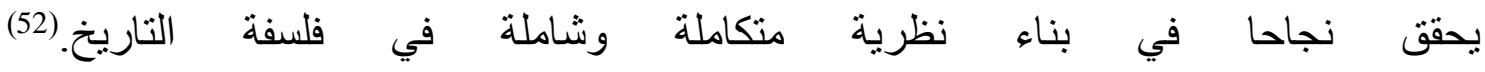
ويبدو ان انطلاقة ابن خلدون ، في تفسير التاريخ ليست هي كما مرت علينا في تناول أوغسطين ، على الرغم من ان تصور ابن خلدون ، للتاريخ لم يكن مغاير ا للدين ، لكنه لم ينطلق منه في تفسير أحداثه ، على العكس تماما من أوغسطين ، الذي قدم تصور ا للتاريخ ، لم يبتعد فيه عن التصور المسيحي للتاريخ ، عندما جعل من المسيح ، هو الذي بسمو بمدينة الأرض الى السماء ، و انه المنقذ او المخلص ـ فكان ابن خلدون ، يعتقد دائما ان الله أراد لسير المجتمع في التاريخ قو انين ثابتة كما في قو انين الطبيعة .

على ان هذه القو انين الطبيعية ، اسهمت في إيمانه بـ (التطور) كنظرية اكتملت لديه قبل داروين ، بخمسة قرون ، فقد اكتشف حقيقة التطور في الكائنات تدريجيا ، حتى الإنسان وصاغها صباغة عملية دقيقة ، وقد استفاد منها في در استه للتاريخ ، حيث رأى ان الظو اهر الاجتماعية أيضا تخضع للتطور فان التطور فيها أكثر وضوحا منه في الظواهر الطبيعية ، والتطور عنده ليس دائريا ،بل لولبي ، لا يسير في خط مستقيم ، وهذا واضح في حديثه عن الدولة ، فكل دولة عنده تبلغ قمة مجدها وحضارتها ثم تهرم وتتدهور لتأتي دولة جديدة لا تبدأ من الصفر بل تأخذ بعض ما تركته الدولة السابقة وتضيف اليه من لديها وتخلق حضارة مختلفة نوعا ما عن الحضارة السابقة . فالتاريخ عند ابن خلدون ،عبارة عن دول تظهر وتنمو ثم تفنى والفناء عنده هو النهاية المحتومة دائما ، وشيء واحد هو الذي يفلت من الفناء ، هو التطور ـ وذهب إلى ان هناك عو امل تتحكم بالتطور التاريخي هي : الاقتصاد والدين و البيئة الجغر افية . (53) هوبئ

ونستنتج ان ابن خلدون نظر الى التاريخ والحضارة من وجهة نظر تطورية حيوية حينما شبه المجتمع بالجسم الحي ، الذي يولا وينمو وينضج ويضعف ويتدهور ويموت ـ ان النظرة الفلسفية

52 - ينظر : عبد الحميد ،صائب ، فلسفة التاريخ في الفكر الإسلامي ، دار الهادي للطباعة والنشر ، ط1، بيروت ، 2007، ص335. 53 ـ ينظر : النشار ،مصطفى حسن ، فلسفة التاريخ ، المصدر السابق ،ص149-157. 
في دراسة التحولات والتبدلات الحضارية تتجلى عند ابن خلدون في رؤيته الكلية للظاهرة التاريخية في سياقاتها التاريخية والطبيعية ، فالبيئة الطبيعية و الجغر افية والمناخ و الخصوبة ، ووسائل انتاج الثروة ، وطريقة تنظين الناس في القبيلة او المدينة ، والعصبية والعقيدة التي لها توحد الجميع ، و القيم الاخلاقية والثروط الاخرى التي تتصل بحياة الناس كلها تؤثر في حياة الناس في صر اعهم مع الطبيعو ومع انفسهم ، ولقد جاءت رؤية ابن خلدون التاريخية حصيلة لتجربة غنية ومعايشة مستمرة للدول والانظمة والشعوب المتصار عة في زمانه ، فأستخلص بأن التاريخ هو " نهوض و انحطاط " للدول من حالة البداوة الى حالة الحضارة ، وان كل نظام يمر بالدور نفسه من الميلاد و النمو و النضج و الانحطاط اشبه بالكائن الحي الذي يولا وينمو ويموت (54) وعلى هذا هنالك اربع مراحل متعاقبة لميلاد الدول وزوالها : البداوة ، الملك ، الحضارة ،

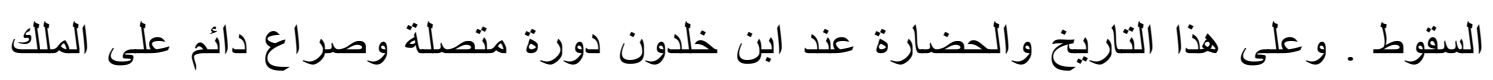
و الرياسة و الحضارة ، و الحضارة هي غاية العمر ان ومنتهاه ، ولكنها سبب خر ابه وزو اله ـ (55) و هذا أيضا يشير إلى ان ، النقد والفحص و التأمل والتدقيق ، كأساليب شاع استخدامها عند ابن خلدون ، لم تفارق بحثه العلمي القائم على أساليب البحث ذاتها المستخدمة في العلوم الطبيعية ، و هذه دلالة انه سبق (أوجست كونت) في محاولة إخضاع العلوم الإنسانية إلى منهج البحث العلمي المستخدم في العلوم الطبيعية ، وهذا سبق أخر له سبق فيه غيره من الفلاسفة الأوربيين و غير هم . وخلاصته في التاريخ وفق تعريفه له في المقدمة " خبر عن الاجتماع الإنساني الذي هو عمران العالم وما يعرض لطبيعة ذلك العمر ان من الأحو ال مثل التوحش و التأنس و العصبيات ... وما ينشأ عن ذلك من الملك والدول ومراتبها وما ينتحله البشر بأعمالهم ومساعيهم من الكسب و المعاش و العلوم و الصنائع وسائر ما يحدث من ذلك العمر ان لطبيعته من الأحو ال ". (56)

54 - عبد العزيز ، عزة ، فلسفة التاريخ و علم الاجتماع ، مكتبة القاهرة الحديثة ، القاهرة ، ط1 ، 1960 ، ص37. 55 - مؤنس ، حسين ، مجلة عالم المعرفة الكويتية ، العدد 34 ، مايو 1978 ، ص178. 56 ـ ابن خلدون ، عبد الرحمن بن محمد، المقدمة ، دار الفكر ، (ب،ط)، بيروت ، 1998، 75. 
و عليه فان فلسفة التاريخ ، ظهرت على مستوى الطروحات الفكرية التاريخية ، بعد ان تحول التاريخ من مستوى التدوين ، الى مستوى التفكير بما هو مدون و إخضاعه الى عو امل تتحكم في مسار اته ، وكانت علامات هذا التحول و اضحة في فكر أو غسطين و ابن خلدون ـ ولكن؟ تم تجاوز هذه المرحلة الى مرحلة جديدة ، هي مرحلة تطور المفهوم حتى ظهر المصطلح بتفسيره الحالي على لسان فولتير ، لذلك تحتم الأمر تسليط الضوء على هذه المرحلة ، وهي مرحلة التطور. و الفهم الفلسفي العقلاني للتاريخ من حيث منطقه الداخلي هو الذي يميز ابن خلدون من سواه ، اذ اتخذ من الظاهر التجريبي الاستقرائي لحظة نقدية لاكتشاف المنطق الداخلي للعملية التاريخية المحكومة بالتبدل والتغير المستمر ، وقد كثف عن قانون التطور الدنياميكي في الحياة والمجتمع ، و ان احوال العالم والامم وعوائدهم ونحلهم لاتدوم على ونيرة واحدة ومنهاج مستقر ، انما هو اختلاف على الايام و الازمنة وانتقال من حال الى حال ـ ولقد اخذ ابن خلدون من الفلسفة نظرتها العقلية الكلية ومن التاريخ و اقعيته ومعطياته الجزئية ، و الاستردادية في منهجه ، ليكون منهما علما و احدا يجذب فيه الفلسفة الى علم الوقائع حتى لا تحلق في سماء اليوتوبيات ، ويجذب فيه التاريخ الى الفلسفة حتى لايصبح مجرد روايات وسرد اخبار جزئية لا رابط بينهما ، فأن الفلسفة دون تاريخ خو اء ، و التاريخ دون فلسفة عماء ـ ان استخدام ابن خلدون المنهج الفلسفي العقلاني النقدي و ادواته الكلية و الديناميكية والتعليل و التحليل الديالكتيكي هو الذي جعله يبني نظرية في التعاقب الدوري للنظم السياسية ـ (57)

المطلب الثاني : تطور المصطلح .

$$
\text { أ - التصور الأوربي للفكر التاريخي قبل فولتير . }
$$

و هنا نلاحظ تطور الفكر التاريخي بشكل ملحوظ على يد الأوربيين ، ذلك لما اقتضاه الواقع الفكري بأوربا وما شهده من تغبير في مناخاته العامة ، وفي الفكر التاريخي ، نستطيع ان نسميها 57 ـ المحبشي ، قاسم عبد عوض ، فلسفة التاريخ في الفكر الغربي المعاصر ، ارنولد توينبي موضوعا ، أطروحة دكتوراه

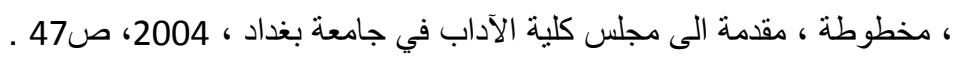


بدايات فلسفة التاريخ ، التي كانت نتاجا من نتاجات عصر النهضة وما شهده من ثورة فكرية على كافة المستويات ، فقد شهد عصر النهضة الاوروبي مجمو عة من الاكتشافات في كافة انواع العلوم و ميادين المعرفة جعلت من اصحاب التاريخ يقررون اللحاق بركاب العلوم ، و هنا كان لز اما عليهم مغادرة الطريقة القديمة في التفكير وانتهاج اسلوب البحث العلمي الجديد الذي تبنته علوم النهضة الاوروبية. " لقد أطلقت النهضة طاقات الإنسان ، وأفضى ذلك الى الاهتمام المتزايد بالحياة الإنسانية ، وبالجسد الإنساني و الطبيعة الحية ، الى رؤية جديدة لكل شيء ، وبدلا من المحنة حل الفرج ، وباستعمال الإنسان للقوى التي وهبها إياه الله حلت الحرية في توجيه العقل بدلا من الخضوع لإر ادة الكنيسة " . (58)

وبهذا المعنى ، فأن عصر النهضة عاد للناس تقدير جديد للتاريخ ، ولم يعد ينظر الى أعمال الإنسان وأفعاله على إنها أعمال لا تستحق الأهمية بالقياس الى مشيئة مقدسة مرسومة تسيطر على الأحداث ، كان من أمر التفكير التاريخي ان عاد تقدير الإنسان ، بوصفه محورا ارتكز عليه التفكير

التاريخي . (59) (1)

" وقد تطورت فكرة التاريخ هذه على يد مفكرين مستقلين ببلاد الغرب في أثناء القرون الأربعة الأخيرة ، تضمنت آر اء جديدة في التاريخ ، ووسعو ا نطاق هذه النظرة الى كافة مجالات التاريخ ، وتوسعوا بهذه النظرة إتباع الفكرة التأليهية في التاريخ ، غير المؤمنين بعلم طبيعة المسيح ، أحرزوا تقدير ا أعظم للقيم الدنيوية في التاريخ ـ وربما أمكن العثور في عصر النهضة بايطاليا على بلى بدايات هذه التأملات المستقلة في التاريخ ـ كما وجدناها في فكرة التحدي عند مكيافللي ". (60) 58 ـ المحبثي ، قاسم عبد عوض ، فلسفة التاريخ في الفكر الغربي المعاصر ، ارنولد نوينبي موضوعا ،المصدر نفسه ، ص252-53.

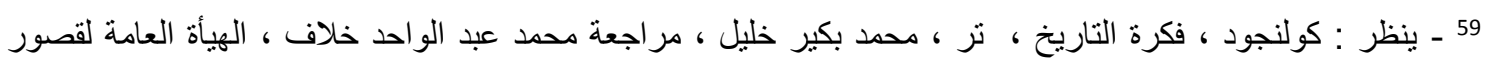

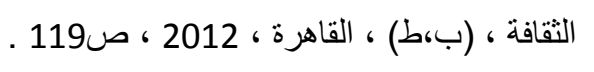
60 ـ الجنابي ، حامد عبد الحمزه ، فلسفة التاريخ عند هيجل وأثزها في منهج البحث التاريخي ، رسالة ماجستير ، مخطوطة

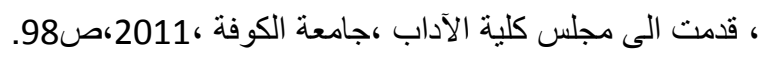


إلا ان من المناسب ونحن نبحث في فلسفة التاريخ في الفكر الأوروبي قبل الاصطلاح ، ان نسلط الضوء على ابرز رواد هذا الفكر التاريخي ، فوجدنا من المهم ان نلقي نظرة على ابعد و اقرب شخصيتين على فولتير خلال عصر النهضة ،هما : مكيافللي ، على اعتباره من أوائل المهتمين بالفكر التاريخي في بدايات عصر النهضة ، والثاني ،هو فيكو ، على اعتباره من معاصري فولتير . مع

أولا : مكيافللي .1527-1467) ـ الذي نجد في مؤلفاته : ( الأمير ، المطارحات ، تاريخ فلورنسا ، فن الحرب ) ، التي أكد فيها " ان كل حركة تاريخية هي حركة سياسية " وان التاريخ من صنع

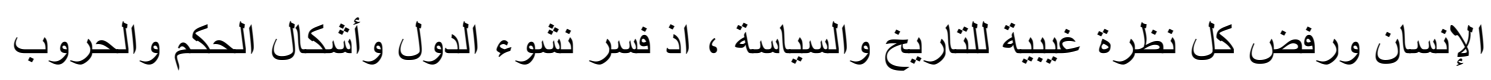
و الأديان بالعودة الى الطبيعة الإنسانية التي لا تستقر على حال أبدا " (61)

وتحيلنا رؤيته هذه الى التاريخ ، على أصالة النزاع في طبع الإنسان ، وان المظهر الأساسي لهذا النزاع ، هو الصراع الأزلي الدائم بين عامة الثعب من جهة وبين العظماء والأقوياء من جهة أخرى ، وان السبب الذي يكمن وراء هذا النزاع هو أرادة القوة والثهوة الى السيطرة عند القلة ، ونتدان الأمن والاستقرار عند الغالبية العظمى ـ وهو في تفصيله أطوار هذا النزاع يبدو مستعيرا لأفكار أفلاطون وأرسطو ، في السياسة المدنية ـ (62) كما ويذهب مكيافللي ، الى انتقاد الكنيسة والتصور اللاهوتي عن الإنسان والتاريخ و الدولة بقوله : " ان المسيحية مجدت الرجال المتو اضعين الميالين الى التأمل والخمول والتبدل ، لا رجال العمل والفعل و النشاط ". (63)

$$
62 \text { ـ } 61 \text { ـ مكيافللي ، الأمير ، تعريب خيري حماد ، منشورات الكتاب التجاري للطباعة ،(ب،ط) بيروت، 1970، ص107. }
$$


لكن مكيافللي ، لم يترك نقده هذا بدون ان يقدم تركيبه الجديد للموضوع بعد ما قام بتحليله ـ فقد أعلن ان "الطبيعة البشرية محكومة بمبدأ ثابت وان عالم الكائنات البشرية هو نفسه في كل مكان وزمان ، انها طبيعة الإنسان الأصلية في الحب والخوف والاعتقاد ، فإذا ما عرف الأمير المصلح ، الطبيعة البشرية ، استطاع التحكم بها و السيطرة عليها " (64) وقد وضع قو انين تحدد رؤيته في تفسير الأحداث التاريخية الكبرى ، فالثورات الكبرى منشؤها عنده الاستضعاف و الاستعباد : " و هكذا كان من الضروري ان يجد موسى شعب إسر ائيل عبيدا في مصر، يضطهدهم المصريون ، لتكون لديهم الرغبة في إتباعه للنجاة من العبودية .. وكان من الضروري أيضا ان يعجز رومولوس ، عن البقاء في ألبا وان يتعرض للعر اء عند ولادته ، حتى يتمكن من ان يصبح ملكا على روما ومؤسسا لنّب فيها .. وكان من الضروري ان يجد كورش ، الفرس ناقمين على إمبر اطورية الماديين ".(65) و هذه النصوص المكيافللية تشير الى عمق فكرة التحدي لديه ، و التحدي كان عدنه تحديا للأفكار الوسيطة السائدة في عصره ، وهذا ما يثير الدهشة ، ومن جانب أخر فأن فكرة التحدي عند مكيافللي ، وجدت بعدا فلسفيا ، امتد الى الفلسفة المعاصرة ، تمثلت في أفكار وفلسفة ارنولد توينبي ، في التاريخ و التي عبر عنها في نظرية التحدي والاستجابة. وهكا يمكن القول ان مكيافللي ، مثل بدايات التفكير الفلسفي في التاريخ خلال عصر النهضة ، و هذا يقودنا الى ان نجد هذا النسق الفكري لاى أفكار الكثير من الفلاسفة الذين اهتموا بدراسة التاريخ مرورا بفيكو ، الذي سوف ندرسه لاحقا. و على ما يبدو ان مكيافللي ، جاء بنظرة جديدة في التاريخ الإنساني ، تعتمد أولا على وحدة الطبيعة البشرية و اطر ادها في كل العصور و الأزمنة ، تاريخها واحدوهو التقدم المستمر نحو مزيد

64 - ينظر : الطعان ، عبد الرضا حسن ، تاريخ الفكر السياسي الحديث ، دار الحكمة للطباعة والنشر ، ط1 وزارة التعليم

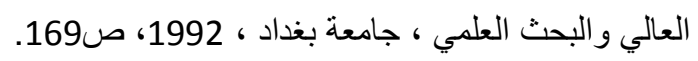

65 ـ ينظر : مكيافللي ، الأمير ، المصدر نفسه ، ص81 . 
من الرخاء او التأخر نحو مزيد من الثقاء ، وتظل الحياة الإنسانية توتر ا بين التقدم والتأخر ـ إذا ما بلغ التقدم مداه تلاه التأخر و إذا ما بلغ التأخر مداه ظهرت بو ادر التقدم ـ ودر اسة التاريخ القديم تثبت هاتين الحركتين اللتين تحددان تاريخ البشرية ثانيا ، يظهر التقدم إذا ما استطاع ذهن عبقري واحد ، و هو الأمير ، وضع نظام واحد يخضع له الجميع والحرص عليه دون ما انحر اف أو تحريف . ويكون هذا النظام قائما على الطبيعة البشرية الثابتة ومعبر ا عنها ، فالثبات فضيلة والتغير رذيلة ، هذان الاقتر احان : ثبات الطبيعة البشرية وقوة المشرع في الحقيقة ، وان كانا عاملين للتقدم إلا إنهما في النهاية يمنعان من كل تقدم ، وبدل ان بصبح النظام وسيلة لسعادة الإنسان ، يصبح الإنسان ضحية للنظام ، ويصبح النظام معوقا لتقدمه . (66)

ثانيا : جيان باتيستا فيكو (1744-1688) ـ يتميز بأهمية خاصة في دراسات فلسفة التاريخ ، ذلك لأنه يعد أبا لفلسفة التاريخ ومؤسسا لها ، بفضل إيمانه بالعناية الإلهية التي لها دورا في التاريخ ، كما ذهب الى ذلك ابن خلدون ، و اقر بتدخل العناية الإلهية في الأزمات وحالات الفوضى ، بإظهار بطل ، فأن لم يكن فبفرد من شعب أخر أرقى فان لم يكن طبقت دور ها الأخير : الفناء أي ان فيكو ، اعترف بدور العناية الإلهية في التطور التاريخي وتدخلها لإصلاحه حينما يتجه الى الفناء ـ وان نقطة البداية عند فيكو في فلسفة التاريخ نقطة منهجية ، إذ بدأ بنقد منهج العلوم الرياضية الذي اعتمد عليه ديكارت ، في فلسفته ومن ثم شغلته مناهج العلوم الطبيعية (67 ) ـ فوجد ان بيكون قد نجح بمنهجه التجريبي في الكثف عن أوثان الفكر وأوهام المفكرين فأر اد ان يستقيد من هذا في در استه للتاريخ من حيث المنهج ، وكان من هذا قوله بأن المؤرخين يتعرضون لأوهام حصر ها في أربعة

66 ـ لسنج ، تربية الجنس البشري، ترجمة وتقيم وتعليق ، حسن حنفي ، دار التتوير للطباعة والنشر والتوزيع ،ط2،

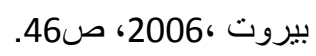

67 ـ وتمكن الى حد بعيد من الإفادة الواعية من التقام الذي طر أ على مناهج البحث و التحليل النقاب في العلوم ، والمعلومات

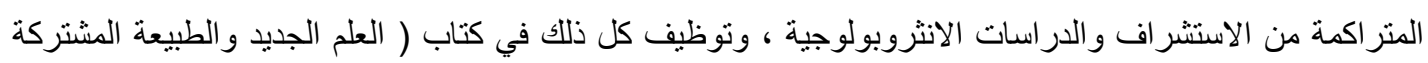

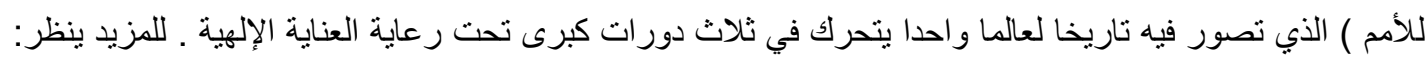

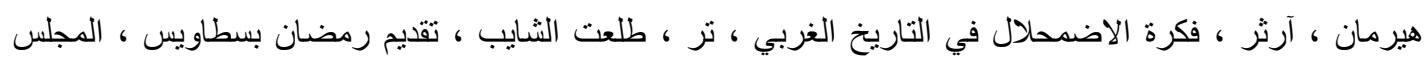

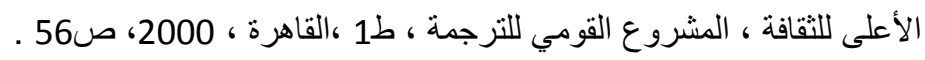


هي : الأوهام الأربعة في عمل المؤرخين وهي ، وهم التهويل و التفخيم و وهم التقافة والتعليم وهم

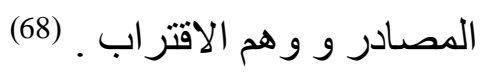
وعنده ، ان التاريخ الإنساني من صنع الإنسان ، ومن ثم يمكن فهمه عن طريق الإنسان . و مبادئ العلم التاريخي لا بد ان توجد في تعديلات العقل الإنساني ، أي في طبيعة الإنسان ـ وان التاريخ يصلح للبحث العلمي والتأمل بسهولة أكثر من الطبيعة الفيزيائية ، فالطبيعة من صنع الله وحده ، وليست من صنع الإنسان ، ولذلك فأن لدى الله وحده معرفة كاملة وكافية بالطبيعة ـ أما المجتمع الإنساني ، و القو انين الإنسانية ، و اللغة ، و الأدب ، فهي جميعها من صنع الإنسان . ولذلك يستطيع الإنسان ان يفهمها بالفعل ويفهم مبادئ تطور ها ـ فالتاريخ يكثف لنا عن الطبيعة الإنسانية . و لا نستطيع ان نبلغ معرفة بالطبيعة الإنسانية بالنظر ، ببساطة ، الى الإنسان على انه يكون في المرحلة الثانية من عصر البشرية مثثلا ، او بأن نأخذ الفيلسوف على انه المعيار ـ انه يجب علينا ان نتجه الى الانكثاف التدريجي لطبيعة الإنسان في التاريخ ، وفي قصائده الثعرية ، وفي فنه ، وفي تطويره للمجتمع والقانون ، و هلم جر ا ـ الإنسان هو الذي يصنع التاريخ ، ومن ثم فأنه يمكن فهمه عن طريق الإنسان . وبدر اسة التاريخ يبلغ الإنسان و عيا تأمليا بطبيعته الخاصة . وبما كان وما كائن وما يمكن ان يكون ـ ومن السخف ان نمجد انجاز ات عصر العقل ، عصر الفلاسفة ونحقر من إن شأن الماضي و العصر البدائي ، لان مجرى التاريخ كله هو انكثاف الإنسان . (69) وفي فكرة التقدم ، عند فيكو ، فأنه يعدها مرحلة منتابعة في حياة كل حضارة منفصلة انه تقدم يصل أحيانا الى أعلى قمم العظمة والقوة ، وفي عصور أخرى ينحدر الى فقدان التضامن البشري و اغتر اب الأفر اد و الجماعات وتفكلك النسيج الاجتماعي و الضعف والتحلل و الكارثة ، و مر احل هذا النظام تحددها العناية الإلهية لكل مجتمع أممي ، لكن ليس هناك غاية نهائية وليس هناك رؤية

68 - ينظر : النشار ، مصطفى حسن ، فلسفة التاريخ ، المصدر السابق ، ص177-178. 69 ـ ينظر : كوبلستون ، فردريك ، تاريخ الفلسفة ،ج6، نر، حبيب الثاروني ، محمود سيد احمد ، مراجعة وتقديم إمام عبد

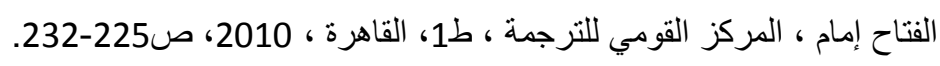


لمسيرة الجنس البشري كله الى كمال نهائي ـ ومع ذلك نستطيع ان نقول ان نظرية التعاقب الدوري لمر احل التطور عند فيكو، لا تحول دون التقلم على ان نفهم التقدم فهما مختلفا عن فلاسفة التتوير ، ذللك لان الدورات التاريخية ، لا تعود بشكل دائري ، بل تعود بشكل حلزوني متقدم ، بحيث يمكن القول بأن إطلاق اسم النظرية الدورية على نظرية فيكو ، هي تسمية غير دقيقة ، لان مفهوم النظرية الدورية يعني ان يعيد التاريخ نفسه وان يبدأ من نفس البداية التي انطلق منها ـ ولكن الأمر مختلف عند فيلسوفنا ، فالتاريخ لا بسير في خط دائري و إنما في شكل حلزوني صاعد بحيث تأتي كل دورة تاريخية بالجديد . (70)

ب - فولتير والتأسيس لقلسفة التاريخ الحديثة.

ويعد فولتير (1694-1778)، أول من استخدم كلمة (فلسفة تاريخ ) بالمعنى الحديث للكلمة ، من حيث هي فرع جديد من فروع المعرفة الإنسانية ، تدرس التاريخ دراسة عقلية ناقدة ، ترفض الخر افات والأوهام والأساطير و المبالغات . وتعود أهمية فولتير، هنا لما كان يمثله في عصر التنوير من قيمة نقدية مهمة ، ففي شخصيته و أدبه الجاد و الساخر وفي منهجه النقدي العنيف ، و أسلوبه اللاذع وقوة أفكاره كان خير من عبر بعمق عن روح عصر التتوير واتجاهاته التقدية ، وكانت نظرته الى التاريخ تمثل ملامح هذه الروحية التقدمية ، فلم يعد ينظر الى التاريخ على انه تسجيل معاهدات ومعارك و أخبار ملوك ، بل اخذ يفكر في ما ور اءه من حكمة . (71) ويرى (فولغين) في كتابه عصر الأنوار ، " ان مؤلفات فولتير، كانت سلاحا في يد الطبقة المتقدمة في ذلك العصر ، و الداخلة في عملية الصر اع الاجتماعي ، وقد وضعته مو اجهته للكنيسة لهن في موقف رفض للتصور اللاهوتي للتاريخ . لقد كان التاريخ في منظور فولتير، علما علمانيا خالصـا بدون تدخل القوى الإلهية ـ انه من صنع أناس عاديين تحركهم دو افع إنسانية خالصة ـ وبما

70 ـ أبو السعود ، عطيات محمد ، فلسفة التاريخ عند جامبا تبستا فيكو ـ التتوير للطباعة والنشر والتوزيع، ط2، بيروت ، 2010، ص198. 71 - ينظر : كولنجود ، فكرة التاريخ ، المصدر السابق ، 148. 
ان الأحداث لا يمكن ان تعد من هذا المنظور مراحل على طريق تحقيق مشروع الهي ، فان فولتير، كثير ا ما بتحدث وكأنه تظافر لمجموعة الظروف المعارضة ـ بيد ان هذه المصادفات ترتبط فيما بينها بعلاقات علمية ـ وتخضع لنو اميس الكون و الطبيعة وذللك لفهم التاريخ البشري . ان هذه النتيجة تقول ، ( كل حدث في الحاضر يولد من الماضي ويولا المستقبل ، وان الترابط السرمدي للأشياء غير قابل للانقطاع او للتغيير وان الطبيعة برمتها خاضعة لنو اميس لاعودة عنها

وتتمظهر أر اء فولتير، في التاريخ والتي أظهرت لأول مرة استخدام كلمة (فلسفة تاريخ) بعد ان استخدمها سابقا في بحث له عام (1756 ) في مقدمة كتابه ( مدخل في طبائع الأمم وروحها ) في (1758-1753) ، ولكنه لم يشرع ببحث مذهبي لهذا المعنى ، الذي يعني ، بالنسبة له ، التفكير في التاريخ بدلالة موقف القرن الثامن عثر العقلي ـ ذلك ان فولتير : " قد ألقى القفاز في وجه ذلك النوع من تصور التاريخ الذي مجده ببر اعة فائقة بوسيه " كان بعتقد في الله ، ولكنه كان يرفض الفكرة القائلة بأن التاريخ كان ثمرة الفعالية الإلهية بالمعنى الذي تثير إليه مثنا ، عبارة كالعناية الخاصة ، و لا شك ان فولتير، لم يكن يعتبر التاريخ من خلال النظرة التاريخية في حياة المسيح . فقد كان خصما صريحا للكنيسة الكاثوليكية . ولم تكن الأديان التاريخية ، بحسب رأيه سوى صيغ خر افية للاين الطبيعي وللمعتقدات و التقوى التوحيدية ـ (73) وفولتير ، هو القائل لا ينبغي ان يكتب التاريخ سوى الفلاسفة ، ومن هذا نرى ان رؤيته في التاريخ تتلخص في ان العقل هو الذي يكمن ور اء حركة التاريخ ، وغريزة الانسان التي تدفعه الى المجتمع يدعمها العقل ـ وثمة ثلاثة اشياء تؤثر على فكر البشر : المناخ ، ونوع الحكم ، و الدين ـ وهذه هي الوسيلة الوحيدة لتفسير لغز العالم ـ (74)

\footnotetext{
72 ـ فولغين ، عصر الأنوار ، دار الطليعة للطباعة و النشر ، ط1، بيروت ، 1981، ص37-38. 73 ـ ينظر : ويدجيري ، المذاهب الكبرى في التاريخ ، المصدر السابق ، ص199. 74 ـ عبد الحميد ، صائب ، فاسفة التاريخ في الفكر الاسلامي ـ دار الهادي ، ط1 ، بيروت ، 2007 ، ص76 .
} 
من هذا يتضح لنا ان المدخل الصحيح لفهم التاريخ لديه هو من خلال ضرورة اهتمام المؤرخ بتتبع سير العقل البشري عبر حقب التاريخ المختلفة دن خلال دراسة منجزاته في العلم والادب و الفن وغير ها من مظاهر الحضارة الانسانية . و اذا بدت هذه الدعوة امرا مألوفا بالنسبة الى القاريء المعاصر ، فأنها لم تكن كذلك في عصر فولتير ، بل كانت بمثابة نقد عنيف للتاريخ الذي شاع طوال العصور الوسطى وحتى عصره ، فقد كان المؤرخون يولون جل اهتمامهم لاخبار ، الدولة و الكنيسة وما يتصل بهما من ملوك وقادة ورجال كهنوت ـ وقد شهدت كتابات فولتير . اللاحقة تفصيلات منتوعة لهذه النظرة الحضارية العقلانية للتاريخ و التي اطلق عليها تسمية فلسفة التاريخ . (75) وفلسفته هذه ادت به الى القول ان التاريخ في اساسه نتاج احتكالك الافكار و الحضار ات ـ فالمسيحية جاءت لتتحدى الوثنية ، و الاسلام دخل في صراع مع المسيحية ، و المذهب البروتستانتي ظهر يتحدى الكاثوليكية التي كانت سائدة في العصور الوسطى ، اما عصر فولتير نفسه فقد تغلب فيه العقل على كل الخر افات وشتى البدع ـ (76) وتعد فلسفته في التاريخ اخلاقية انسانية ، اذ ذهب من خلال فلسفته في التاريخ هذه الى ان التاريخ لايهدف الى اثباع الفضول ولا تجميع الوقائع ، ولكنه البحث في المثل التي تفيد في التحكم في المستقبل ، ومع ذلك كان يرى ان التاريخ وحده لايكفي كمرشد للسلوك الخلقي ، وان الادب له هذه الميزة على التاريخ ـ (77) وقد خاض في فكرة التقدم ، حيث حاول فولتير، وضع قانون للتقدم على مرحلتين : الأول عهد الفطرة الخالصة ـ عاش فيه الإنسان عاقلا طبقا لقانون الفطرة يتمتع فيها بنتيجة عمله ويحترم فيها حقوق الآخرين ، و الثانية عهد المدينة ، يعيش فيها الإنسان تحت نظام من صنعه ويحول فيه قانون الفطرة الى نظام اجتماعي يقوم على الحرية و العدل ـ قد تحدث انحر افات في مسار العقل وفي تقدم

75 ـ الملاح ، هاثم يحيى ، الوسيط في فلسفة التاريخ ـ دار ابن الاثير للطباعة والنشر ، (ب،ط) جامعة الموصل ، 2007 ، ص158 7677 ـ عبد الحميد ، صائب ، فاسفة التاريخ في الفكر الاسلامي ـالمصدر السابق ، ص76 ـ 
الإنسانية و على رأسها الطبقات الاجتماعية واستغلال الملكيات الكبيرة واضطهاد الأجناس البشرية و الاضطهاد الديني ، ومع ذلك فالإنسانية قادرة على التغلب على هذه الانحر افات والاستمر ار في تقدمها بفضل المدنية و النظم الاجتماعية القائمة على الحرية و العدالة ـ وللتقدم غايات ثناث : أولا : التقدم العقلي و هو أساس التقدم في النواحي الأخرى ، وهو ما ركزت عليه فلسفات التتوير جميعها في محاربتها لألوان الجهل ـ ثانيا : التقدم الاجتماعي خاصة في العادات و التقاليد و اكتساب الإنسان سلوك التحضر و المدنية ـ ثالثا : التقدم في التشريع ، و إقامة النظم الاجتماعية على العدالة وعلى الديمقر اطية في أساليب الحكم . (78) و عنده تبقى حركة التاريخ في تقدم ، فأن الانتصار ات البشرية على الاثياء وتناحر الجماعات البشرية وتقدم الاخلاق و العلوم و الفنون ، كل هذا جرى بصورة طبيعية ، وكل هذا سيستمر منز ايدا كلما توسع افق العقل البشري . (79) ولفولتير عدة مصنفات تاريخية ، منها : تاريخ شارل الثاني عشر ملك اسكيندناوة ، و عصر لويس الرابع عشر ، وتاريخ نشأة المسيحية ، وحوليات إمبراطورية روسيا خلال حكم بطرس الأكبر . وتميز منهج فولتير، في البحث التاريخي بميزات عدة ، أبرزها : البراعة في تحليل الثخصيات وحو ادث التاريخ و المقارنة بينها و الاهتمام بتاريخ الحضار ات لا بتاريخ الملوك و الساسة ، حتى في كتبه التي تناول فيها عصور بعض الملوك ، فمعنى التاريخ عنده يكمن في العلوم والفنون والأدب وتهذيبات الحياة الاجتماعية ـ اذ هو صورة للحضارة وتفسير لها ـ كما وأدرج التاريخ البشري بأجمعه ضمن دائرة البحث والدراسة والنظر الفلسفي ، وعدم الاقتصار في ذلك على التاريخ الأوروبي ـ كما وذهب الى التفسير الواقعي لحوادث التاريخ بعيدا عن غيبيات الكتاب المقدس ، ومن ثم نجد ان فولتير انتقد نقدا لاذعا تاريخ اليهود الذي أورده العهد القديم ، على أساس انه جاء بكل ماهو غبي ، وبعيدا عن الواقعية ، مما جعله عرضة للنقد ، بسبب قصور نصوصه وعدم

78 ـ لسنج ، تربية الجنس البشري ، المصدر السابق ، ص58-59. 79 ـ عبد الحميد ، صائب ، فاسفة التاريخ في الفكر الاسلامي ـ المصدر السابق ، ص76 . 
مطابقتها و عدم قدرتها على الاتصال بالمنهج التاريخي ، وعليه فأن فولتير، الذي تميز بفلسفته العقلية انتقد تاريخ اليهود . (80)

الخاتمة نتيجة لاشتغالاتتا في هذا البحث تم التوصل الى نتائج اساسية تعد خاتمة البحث وهي كالتالي :

1 - تعد فلسفة التاريخ قبل الاصطلاح من الموضو عات التي كان لها حضور ا مميز ا في الفكر القديم ، وبر غم عدم اصطلاحها بهذا الاسم الا ان هذا لايعني عدم حضور ها قديما .

2 - كما ان للفلسفة جذور شرقية ، فقد تبين لنا من هذا البحث ان لفلسفة التاريخ وحركة العقل اصول شرقية قديمة ، كما لحظنـا ذلك ضمن در استنا لحركة التاريخ عند البـابليين والمصريين و الصينبين ، اذ لم يكن اهتمامهم قاصر ا في التفكير التاريخي على وفق نوع المرحلة الفكرية التي كانوا قد تأثرو ا بها .

3 - تبين ان هناك نوع من الملاقحة الفكرية و الحضـارية بين حضـار ات الثرق القديم ، ممـا ادى الى تأثر احداها بالاخرى ، فكانت فكرة التاريخ تحتل اهمية بالغـة في ثقافة تلك الامم القديمـة ممـا ادى الى حضور ها الفاعل في البناء التاريخي .

4 - لم تكن الفلسفة اليونانية و الفكر التاريخي اليوناني اقل شأنا من حضـار ات الثرق في طريقة التعاطي مع الافكار التاريخية ، فحظى التاريخ لديهم باهتمامات واسعة وصلت الى كتابته شـعرا داخل الملحمـة ، وشـاهدنا هذا عند هوميروس ، وهزيود ، فوجدنا اشـار ات الى قـانون السببية التاريخية وقانون العلية ، كما ووجدنا اثرا لمنهج تاريخي استعطله اهل اليونان في كتابتهم للتاريخ

5 - كان للقديس او غسطين ، و العلامة ابن خلدون بصمة و اضحة ومميزة في مجال فلسفة التاريخ فبل الاصطلاح ، فما زال فكر هما مؤثرا في طريقة التفكير التاريخي عند الفلاسفة والمؤرخين ، 80 - ينظر : النجار ، موسى جميل ، فلسفة التاريخ ، المصدر السابق ، ص92. 
ولا شك انهما سبقى فلاسفة العصر الحديث من مكيافللي الى فر انسيس فوكوياما ، في الذهاب الى تفسير التاريخ بطريقة علمية اتفقت مع فلسفة كل منهما .

6 - وجدنا ان فلسفة التاريخ في العصر الحديث قبل الاصطلاح قد اخذت طابعا مختلفا تمامـا عن طريقـة التفكيـر بالتـاريخ بـالمنهج القديم القـائم على المـنهج الارسـطي ، المسـتند الـى المـنهج الاستنباطي ، فقد مات هذا المنهج في نظر فلاسفة العصر الحديث ، و اتبعوا المنهج الاستقرائي الجديد القائم على المنهج العلمي ، و الذي يستند الى خطوات منهج البحث العلمي .

7 - تم اصطلاح فلسفة التاريخ على لسان فولتير ، بعد ان استبدل كلمة حكمة التاريخ بكلمة فلسفة التاريخ ، وجاء بار اء جديدة بطريقة التفكير بالتاريخ اختلف فيها عن سـابقيه ، وقد جاء في اول خطو اته ان لاصدفة في التـاريخ ، وان التـاريخ تحكمه اسباب ونتائج ، ويعد فولتير مـ ابرز فلاسفة العصر التنويري ، الذي ذهب الى مغادرة الماضي بكل ألياته القديمة في طريقة التفكير ، و الذهاب الى وجود حكمة في التاريخ ومن در اسـة التاريخ ، فأخذ يبحث عن الحكمـة مـن در اسـة التاريخ ، من خـلال استعمال النظرة الفلسفية التاملية و التحليل النقدي القائم على تفحص روح النص التاريخي والواقعة التاريخية ، وفولتير يحنل اهمية كبرى للارس في فلسفة التاريخ ، لانها حمل ايدلوجيات عصر بكامله ومثل تلك المرحلة الانتقاليـة من مراحل عصر النهضـة العلميـة ، وفي هذه النهضة قدم لنـا فولتير ، نموذج النهضـة الادبيـة التي رافقت تلك النهضـة العلميـة التي شهدتها اوروبا في شتى انواع المعارف وميادين العلوم قائمة المصادر والمراجع

1. ابن خلاون ، عبد الرحمن بن محمد، المقدمة ، دار الفكر ، (ب،ط)، بيروت ، 1998.

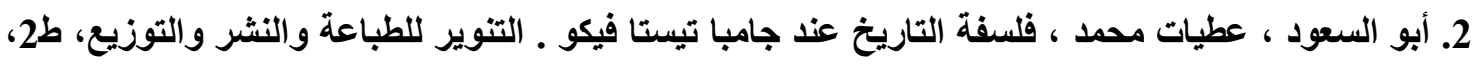

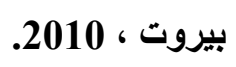

3. ادهم ، علي ، تاريخ التاريخ ، (ب،ن) ، (ب،ط)، القاهرة ، 1977 ـ

4. ارنست ، كاسيرر، مدخل الى فلسفة الحضارة الانسانية ـ تر، إحسان عباس، دار الاندلس ، بيروت ، 1961. 
5. الالوسي ، حسام الدين ، الزمان في الفكر الديني والقلسفي القديم ، المؤسسة العربية للاراسات والنشر ،

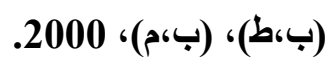

6. الجابري ، علي حسين ـ فلسفة التاريخ في الفكر العربي المعاصر ، جلية الأصالة والمعاصرة ، القسم الأول ،

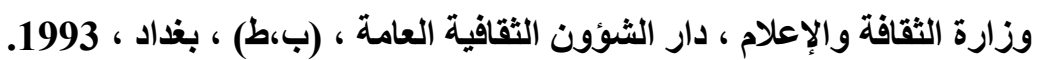
7. الجنابي ، حامد عبد الحمزه ، فلسفة التاريخ عند هيجل وأثرها في منهج البحث التاريخي ، رسالة ماجستير ، مخطوطة ، قدمت الى مجلس كلية الآداب ،جامعة الكوفة ، 2011 ، 8. الخضيري ، زينب محمود ، فلسفة التاريخ عند ابن خلدون ، دار التنوير للطباعة والنشر والتوزيع ، (ب،ط)، ، بيروت ، 2009.

9. الاليمي ، حامد حمزه حمد ـفلسفة التاريخ والحضارة .دار الطيف للطباعة ، (ب،ط) ،واسط ، 2004 ـ 10. السعيدي ، حميد خلف ، دروس في فلسفة التاريخ ـ دار أبجد ، (ب،ط) ، بغداد ، 2007.

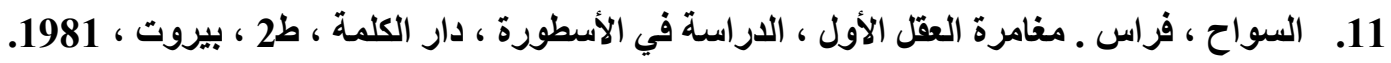

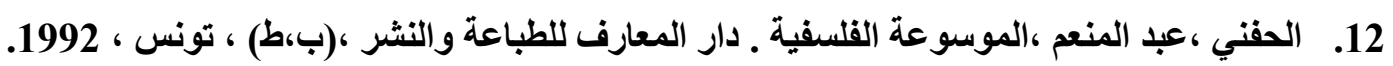
13. الثيخ ،غنمي ، فلسفة التاريخ ،دار الثقافة والنشر والتوزيع ، (ب،ط)، القاهرة ، (ب،تون).

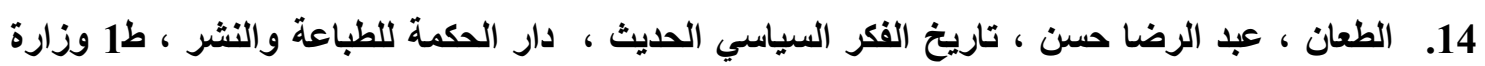

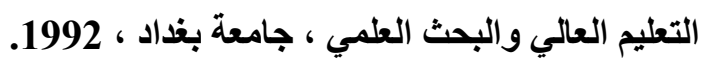

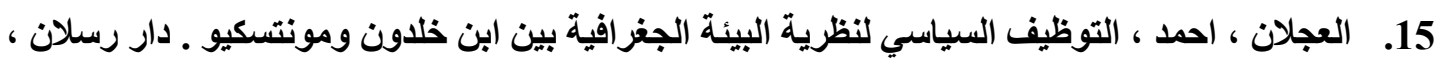
ط1، دمثق ، 2009.

16. الكتاب المقدس ، العهز الجديد ، الإصدار الرابع ، (بكن) ، الإصدار الرابع ، ط30، (ب،م) ، 1993.

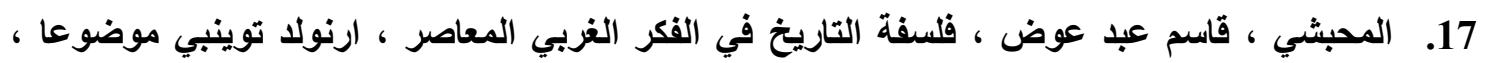
أطروحة دكتوراه ، مخطوطة ، مقدمة الى مجلس كلية الآداب في جامعة بغداد ، 2004 ،

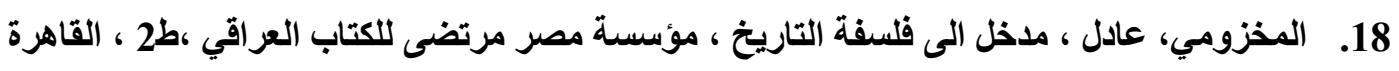
.2010،

19. المزوري ، زاهدة محمد الثيخ طه ، اركولوجيا فلسفة التاريخ ،المسار التطوري لقلسفة التاريخ .دار مكتبة البصائر للطباعة والنشر والتوزيع، (ب،ط)، لبنان ، 2012.

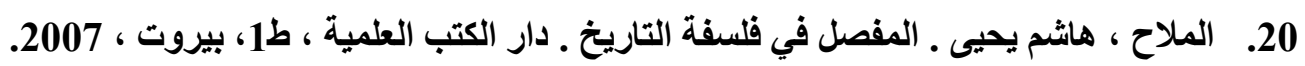


21. الملاح ، هاثم يحيى ، الوسيط في فلسفة التاريخ ـ دار ابن الاثير للطباعة والنشر ، (ب،ط) جامعة

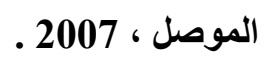

22. الملاح، هاشم يحيى ، واخرون ، دراسات في فلسفة التاريخ ، مديرية دار الكتب للطباعة والنشر ، (ب،ط)

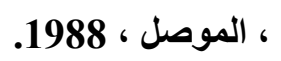

23. النجار ، جميل موسى ، فلسفة التاريخ ، مباحث نظرية ـ المكتبة العصرية ، ط1، بغداد ، 2007.

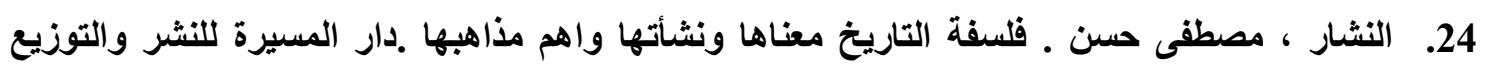

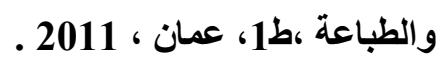

25. باقر، طه ـ ملحمة جلجامش ـ منشورات وزارة الاعلام ، الجمهورية العراقية ، سلسلة الكتب الحليثة ،

$$
\text { (ب) (ب) (ب) ، بذاد ، } 1975 .
$$

26. باقر، طه، في مقدمة ترجمته لكتاب ارنولد توينبي ،بحث في التاريخ،موجز المجلات الستة الأولى ،بقلم سي. سمرفل ،الجزء الأول ،مطبعة التفيض الاهلية ، ،بغداد،(ب،تات).

27. برستد ، انتصار الحضارة ، ترجمة احمد فخري ، مكتبة الانجلو المصرية ، (ب،ط) القاهرة ، 1962.

28. تسيمير ، رويرت ، في صحبة الفلاسفة ، ج2 ، تر ، عبد الله محمد ابو هشة ، دار الحكمة ، ط1 ، لندن ،

29. توينبي ، ارنولد ، تاريخ البشرية ،ج2 ، تز ، فؤاد محمد شبل ، الادارة الثقافية في جامعة الدول العربية ،

لجنة التأليف والترجمة والنشر ، ط1، القاهرة ، 1961.

30. توينبي ،ارنولا ، الفكر التاريخي عند الإغريق ،ترجمة لمعي المطيعي ، مراجعة محمد صقر خفاجة ، الهيأة المصرية العامة للكتاب ، ط2، القاهرة ، 1990.

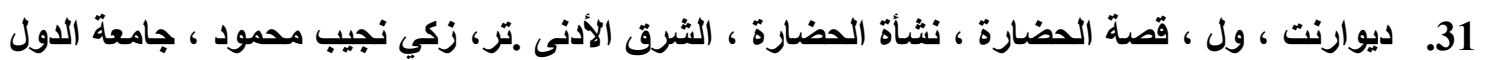

العربية ،الإدارة الثقافية ، ظ3 ، القاهرة ، 1965.

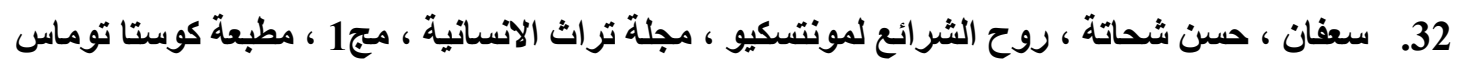
وشركاؤه ، القاهرة (ب،تان)

\footnotetext{
33. شايلا ، جوردن ، التاريخ ، تز ، علألي برسوم عبد الملك ، (ب،ن) ، (ب،ط) ، القاهرة ، 1958.

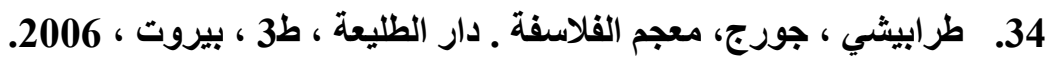

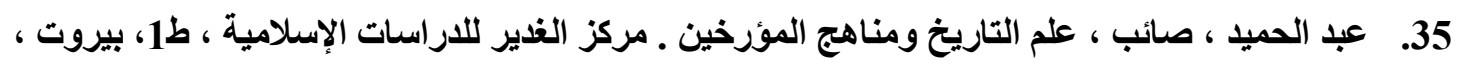


36. عبد الحميد ،صائب ، فلسفة التاريخ في الفكر الإسلامي ، دار الهادي للطباعة والنشر ، ط1، بيروت ،

37. عبد الحي،عمر،الفكر السياسي في العصور القديمة.مجد المؤسسة الجامعية للاراسات والنشر والتوزيع ،2 طبيروت،2006.

38. عبد زيل ، عامر ، التأويل اللاهوتي للتاريخ عند اوغسطين ـ ضمن كتاب فلسفة التاريخ جدل البداية والنهاية والعود الدائم ـ الرابطة العربية الاكاديمية للفلسفة ، اشراف وتحقيق علي عبود المحمداوي ، ، ابن النديم للنشر والتوزيع ، دار الروافد الثقافية ـ ناشرون ، ط1 ، بيروت ـ 2013. 39. فولغين ، عصر الأنوار ، دار الطليعة للطباعة والنشر ، ط1، بيروت ، 1981،. 40. قاسم ، عبده قاسم ، تطور مناهج البحث في الدراسات التاريخية . ، مجلة عالم الفكر ، المجلد 20 ، العدد .199-198 1

41. كريمر ،صوئيل ، من ألواح سومر ، تر، طه باقر ، مكتبة مثنى الخاتجي ، (ب،ط) ، بغداد ، 1957 ، 195

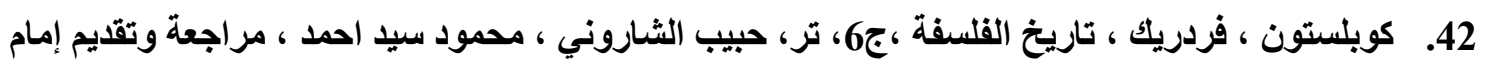

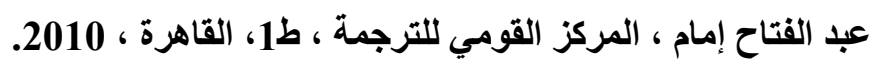

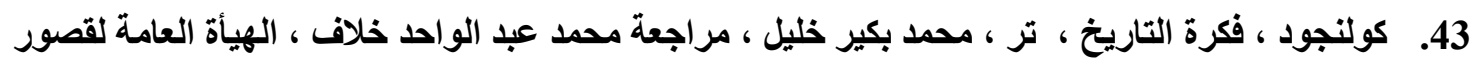
الثقافة ، (ب،ط) ، القاهرة ، 2012.

44. لسنج ، تربية الجنس البشري، ترجمة وتقديم وتعليق ، حسن حنفي ، دار التنوير للطباعة والنشر

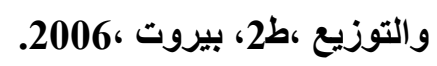

45. معلوف ، لويس ، المنجد في الاعلام . مؤسسة انتثارات دار العلم ، ط26 ، طهران ، (ب،ت) . 46. مكيافللي ، الأمير ، تعريب خيري حماد ، منشورات الكتاب التجاري للطباعة ،(ب،ط) بيروت، 1970. 47. هرنشو ، علم التاريخ ، تر، عبد الحميد العبداوي ، (ب، ن) ، (ب،ط) ، القاهرة ، 1937.

48. هورس ، جوزف ، قيمة التاريخ ، تز ، الثيخ نسيب وهبة الخازن ،(ب،ن)، (ب،ط)،بيروت ،

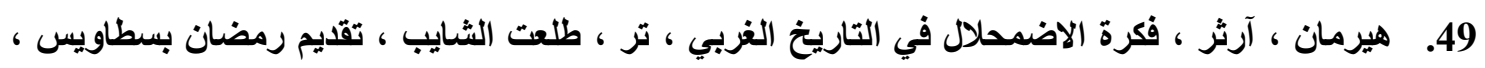

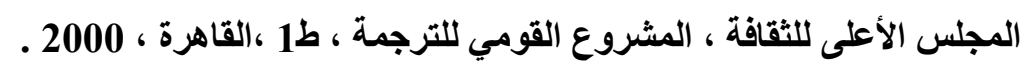

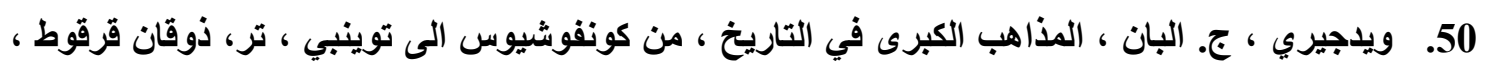
دار القلم ، ط2، بيروت ، 1979. 
51. ويلسون ، كولن ـ جرانت ،جون ـ فكرة الزمان عبر التاريخ ، ترجمة فؤاد كامل ، مراجعة شوقي جلال ،

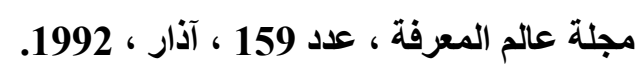

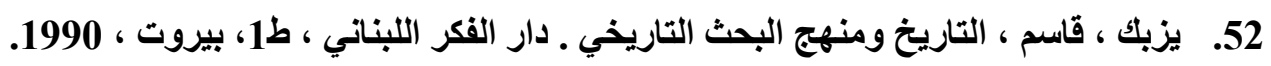

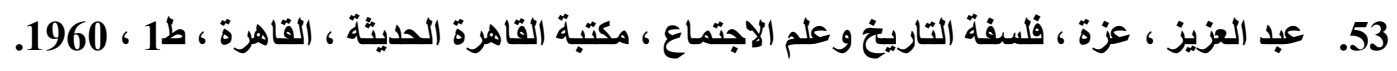

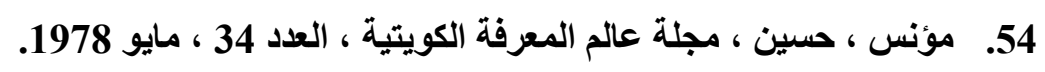
55. 56. 53. Collingwood. R.G. ; The Idea of History (Oxford). 1946. 